\title{
Ciudadanos y actitudes punitivas: Un estudio piloto de población universitaria española.
}

\author{
Daniel Varona Gómez \\ Profesor titular de Derecho Penal \\ Universitat de Girona ${ }^{l}$
}

\section{RESUMEN}

Uno de los "temas estrella" de la criminología del siglo XXI es la investigación sobre las actitudes punitivas de los ciudadanos. Ello deriva fundamentalmente de la creciente preocupación ante el fenómeno conocido por la literatura criminológica como "populismo punitivo", en el que parecen inmersos muchos países desarrollados, y uno de cuyos motores o características sería precisamente la (supuesta) demanda social de una respuesta más severa frente a la delincuencia. Existen ya abundantes investigaciones en la literatura comparada que permiten desmentir o por lo menos matizar el pretendido mayor punitivismo de la sociedad actual, pero en nuestro país no se han realizado hasta la fecha investigaciones con la misma profundidad que permitan establecer algunas conclusiones sólidas sobre las actitudes punitivas de los ciudadanos españoles. El propósito del trabajo es presentar un estudio piloto sobre la actitud punitiva de los ciudadanos a partir de una encuesta realizada a la población universitaria de Girona relativa a su actitud frente a la prevención y el castigo de la delincuencia.

\section{ABSTRACT}

One of the "major topics" of the criminology of the 21 st century is the research on the punitive attitudes of the citizens. It derives fundamentally from the increasing worry before the phenomenon referred by the criminology literature as "penal populism", which is apparent in many developed countries. One of the characteristics of "penal populism" is that of (supposed) social demand of a more severe response to the delinquency. However certain research conducted with regard to public opinion and punitive attitudes in various countries negates or at least qualify the supposed greater citizen punitivism. In Spain there is a lack of research about public opinion and punitive attitudes. The purpose of the work is to present a pilot study on the punitive attitude of the citizens from a survey carried out by the students of the University of Girona.

\footnotetext{
1 El origen de este trabajo es un estudio realizado con Gonzalo Escobar (accesible en http://www.gencat.net/justicia/temes/cejfe/recerca/cateleg/cronologic/inv2007/index.html). Josep Cid y Juanjo Medina me ayudaron a planificar la investigación. Lorena Antón realizó la explotación estadística de los datos de la encuesta (mediante el programa informático SPSS). Mención especial merece Joel Martí que ha demostrado en infinidad de ocasiones su paciencia para ayudarme a entender y presentar adecuadamente los resultados del estudio. A todos ellos quiero expresarles mi más sincero agradecimiento. Este estudio se inscribe en el proyecto de investigación "La credibilidad de las penas alternativas" (SEJ2005-08955-C02-01) y también ha contado con la ayuda prestada por la Generalitat de Cataluña a los grupos de investigación consolidados (Grupo de Investigación en Criminología Aplicada a la Penología, resolución AGAUR, 18 octubre 2005, SGR 08024) y por el Centre d'Estudis i Formació Especialitzada de la Generalitat de Catalunya (convocatòria d'ajuts econòmics per a la realització de projectes d'investigació en els àmbits d'execució penal, any 2006).
}

Revista Española de Investigación Criminológica

Artículo 1, Número 6 (2008) $\quad$ www.criminología.net

ISSN: $1696-9219$ 


\section{Introducción: presentación de la investigación realizada.}

Uno de los "temas estrella" de la criminología del siglo XXI es la investigación sobre las actitudes punitivas de los ciudadanos. Nunca antes la literatura criminológica, fundamentalmente en los países anglosajones, se había preocupado tanto por tratar de evaluar la opinión pública sobre el funcionamiento del sistema penal en global; es decir, la delincuencia como tal (sus causas, las posibilidades de prevención, etc.), su "tratamiento" por parte del sistema (castigos -tipo, intensidad, etc. -), y las diversas instituciones que intervienen en este proceso (jueces y tribunales, fiscales, policía, prisiones, etc. $)^{2}$.

Probablemente este interés por analizar y evaluar las actitudes punitivas de los ciudadanos deriva de la creciente preocupación ante el fenómeno conocido en la literatura criminológica como "populismo punitivo", en el que parecen inmersos muchos países desarrollados, y uno de cuyos motores o características sería precisamente la (supuesta) demanda social de una respuesta más severa frente a la delincuencia ${ }^{3}$.

Es decir, cuando la apelación al "clamor popular" parece haberse convertido en una de las directivas básicas del diseño de la política criminal actual, se hace imprescindible saber exactamente qué demandan los ciudadanos del sistema penal. Lo que está en juego es, en últimas, determinar si los políticos están realmente respondiendo a lo que demandan los ciudadanos y si de hecho aquello que éstos quieren parte de conocimientos reales sobre el sistema penal o más bien de creencias que no responden a la realidad. Comprobar esto implica obviamente llevar a cabo investigaciones sobre las actitudes punitivas de los ciudadanos ${ }^{4}$.

\footnotetext{
${ }^{2}$ ROBERTS/HOUGH (2005:3) hablan de un "aumento muy importante del volumen de investigación sobre las actitudes ciudadanas hacia el sistema penal" a partir del comienzo de los años 90 del siglo pasado.

${ }^{3}$ Sobre el "populismo punitivo", en nuestro país vid. por todos LARRAURI (2005 y 2006) y DÍEZ RIPOLLÉS (2004 y 2005, que ha denominado a este nuevo modelo de sistema penal caracterizado por el "populismo punitivo" como "Derecho Penal de la Seguridad Ciudadana" en contraposición con el tradicional "Derecho Penal Garantista").

4 Ésta es una afirmación compartida en la literatura criminológica comparada. Vid. así ROBERTS/STALANS/INDERMAUR/HOUGH (2003:167-168), destacando la necesidad de mejorar la
}

Revista Española de Investigación Criminológica

Artículo 1, Número 6 (2008) $\quad$ www.criminología.net

ISSN: $1696-9219$ 
La investigación sobre las actitudes punitivas de los ciudadanos es especialmente necesaria en nuestro país, porque no contamos con estudios como los realizados en otros países que han podido documentar de manera detallada que en realidad puede hablarse del "mito del punitivismo ciudadano" (MARUNA/KING, 2004: 87 y ss.). Ello es así porque lo que estas investigaciones sobre actitudes punitivas han podido demostrar es que definir de forma categórica a la opinión pública como punitiva es una forma simplista y equivocada de describir la situación, ya que el asunto es mucho más complicado y sutil de lo que una única etiqueta puede revelar (MARUNA/KING, 2004:87 y ss.). Por otra parte, la literatura criminológica también subraya que los ciudadanos, enfrentados ante la tarea de decidir una pena para un caso concreto, no imponen ni mucho menos penas más severas que las impuestas en la realidad forense por los jueces y tribunales penales (ROBERTS/STALANS/INDERMAUR/HOUGH (2003:29 y ss.). La cuestión es si también en España el punitivismo ciudadano es un mito, que se alimenta de creencias erróneas y que es utilizado (intencionalmente o no) por los partidos políticos en su "cruzada" contra el crimen.

Ciertamente, en nuestro país contamos con toda una serie de fuentes de datos (Eurobarómetros, Estudios del Centro de Investigaciones Sociológicas, Estudios del Consejo General del Poder Judicial, Encuestas de Victimación) que nos aportan conocimiento sobre la visión ciudadana del funcionamiento del sistema penal y sus actitudes punitivas ${ }^{5}$, pero hasta la fecha no existen en España investigaciones específicamente dirigidas a evaluar las actitudes punitivas de los ciudadanos. Lo que pretendo con la investigación que ahora se presenta es dar un primer paso en este sentido.

medición de las actitudes ciudadanas hacia el sistema penal, ya que "La medición superficial de la opinión pública es parte del proceso que apoya el populismo punitivo".

5 No puedo, por cuestiones de espacio, detenerme a tratar con detalle la información que sobre las actitudes punitivas de los españoles nos aportan esas fuentes de datos. Baste en este momento decir (para más detalle, vid. VARONA, 2008) que todos esos estudios permiten concluir que los ciudadanos españolas, como sus homólogos europeos, tienden sistemáticamente a creer que la delincuencia está en continuo aumento y que el trato que reciben los delincuentes por parte del sistema penal es demasiado benévolo. Pero por otra parte, las encuestas de victimación que se han realizado en algunas partes del territorio español (vid. para Málaga, DÍEZ RIPOLLÉS/GIRÓN/STANGELAND/CEREZO, 1996; y para 2006 GARCÍA/PÉREZ/BENÍTEZ, 2006:167 y ss; vid. para Cataluña, LUQUE, 1999:159 y ss.,) o incluso en toda España (vid. EU ICS, 2005), acreditan que, ante un caso escenario hipotético, los ciudadanos españoles se decantan por aplicar una pena que es bastante más benévola que la que en la realidad aplican los jueces en casos similares.

Revista Española de Investigación Criminológica

Artículo 1, Número 6 (2008) $\quad$ www.criminología.net

ISSN: $1696-9219$ 


\section{Método}

La base del estudio que se presenta es un cuestionario implementado como anexo al British Crime Survey de 1996 (vid. HOUGH/ROBERTS, 1998). Éste fue el "instrumento" escogido porque se trata de un cuestionario diseñado específicamente para tratar de captar la opinión ciudadana con respecto al funcionamiento del sistema penal y sus actitudes punitivas. No obstante, dicha encuesta, en el proceso de traducción y adaptación a la realidad española y a objetivos particulares de la investigación sufrió algunos cambios significativos, que nos permiten decir que el cuestionario finalmente distribuido es en parte "original"6.

Una vez confeccionado, el cuestionario final fue distribuido postalmente (vía email) a una muestra constituida por la población universitaria de la Universitat de Girona $^{7}$. En concreto, los datos de la muestra son los siguientes:

- Muestra: población universitaria (UdG). Descripción muestra:

- $\quad \mathrm{N}$ (población total $)=12034$

- $\quad \mathrm{z}$ (nivel de confianza) $=2$

- $\mathrm{e}($ margen de error $)=0,049$

- $\mathrm{P}=\mathrm{Q}($ varianza poblacional $)=50 \%$

- $\mathrm{n}$ (población encuestada $)=813$

Ciertamente, la metodología escogida para realizar nuestra investigación debe afrontar dos problemas principales. En primer lugar, la cuestión de la representatividad

\footnotetext{
${ }^{6}$ En primer lugar hubo que "depurar" ciertas preguntas que no se adaptaban a la realidad criminal española. En segundo lugar se añadieron preguntas para tratar de adaptar el cuestionario original a los últimos conocimientos sobre actitudes punitivas (en particular por lo que se refiere a las "causas" del punitivismo, sobre la base del estudio de MARUNA/KING, 2004). Y en tercer lugar, se introdujeron preguntas para tratar de alcanzar objetivos específicos de la investigación (por un lado, la opinión ciudadana sobre las penas alternativas a la prisión, y por otro lado, la relación que los ciudadanos detectaban entre inmigración y delincuencia).

${ }^{7}$ La distribución "informática" de la encuesta (mediante el envío de un correo electrónico en el que se informaba de la investigación y se ofrecía el acceso a una dirección de internet donde se encontraba el cuestionario, que era auto-rellenado) se realizó entre el último trimestre de 2006 y el primer trimestre de 2007.
}

Revista Española de Investigación Criminológica

Artículo 1, Número 6 (2008) $\quad$ www.criminología.net

ISSN: $1696-9219$ 
de la muestra. Hay que dejar claro que el sistema elegido para la distribución del cuestionario, por cuestiones presupuestarias, se basó en el simple envío postal (vía email) del mismo a toda la muestra. No se hizo, por tanto, un muestreo por cuotas para tratar de hallar un grupo representativo al que entrevistar personalmente. Por lo tanto, ciertamente no podemos asegurar que los que respondieron el cuestionario estuvieran particularmente sensibilizados (en uno u otro sentido) con el tema de la delincuencia y por ello hemos de ser muy cautos a la hora de generalizar los resultados de nuestra muestra. Por otra parte, la tasa de respuesta al cuestionario enviado postalmente fue (como sucede habitualmente) baja (menos del 10\%), a pesar de lo cual el número final de encuestas $(n=813)$ es lo suficientemente elevado como para realizar análisis estadísticos.

En segundo lugar, otro problema importante que ha de hacer frente nuestra investigación hace referencia a si se trata o no de una muestra demasiado sesgada por el hecho de tratarse de una población universitaria. En particular, algunas investigaciones (vid. por ejemplo, MARUNA/KING, 2004:98) sugieren que la educación es una variable a tener en cuenta a la hora de explicar las actitudes punitivas de la población (en el sentido de que a mayor nivel educativo menor actitud punitiva). Creemos, no obstante, que hay motivos para pensar que en todo caso estaríamos ante un sesgo no muy significativo que no debería así afectar de forma relevante a la investigación ${ }^{8}$. Pero ciertamente ésta es sólo una hipótesis. Sólo cuando contemos con una muestra general de la población los resultados que ahora analizaremos podrán tener validez general ${ }^{9}$.

\footnotetext{
${ }^{8}$ Esos motivos son, básicamente, los dos siguientes: primero, existen investigaciones criminológicas que aunque ciertamente subrayan el papel de la educación en la conformación de actitudes punitivas, no le atribuyen un papel primordial (vid. MARUNA/KING, 2004:98-99). Segundo, los resultados de nuestra investigación son muy similares, en cuanto a la actitud punitiva frente a un caso escenario concreto (el caso escenario 1 en nuestra investigación, que es de hecho el caso escenario tipo en las encuestas de victimación realizadas en nuestro país), a los documentados en algunas encuestas de victimación realizadas a la población general (vid. por ejemplo, GARCÍA/PÉREZ/BENÍTEZ, 2006:167 y ss.; sobre una encuesta de victimación realizada el año 2006 en Málaga). Si acaso en nuestra investigación (siempre por lo que respecta a ese caso escenario concreto), se documenta una actitud más punitiva que la hallada en algunas encuestas de victimación realizadas a la población general (por ejemplo, para Cataluña, la que documenta LUQUE, vid. LUQUE, 1999:159 y ss.).

9 En el curso de la investigación que como se ha mencionado tiene como muestra a población universitaria se realizaron también una serie de entrevistas personales a ciudadanos seleccionados aleatoriamente. El objetivo de esta pequeña investigación paralela era tratar de saber, aunque sólo indiciariamente, si los resultados de la muestra universitaria diferían en gran medida de la del resto de la población. En concreto se realizaron 98 entrevistas y los resultados indican que la muestra de población general tenía una actitud ligeramente más punitiva que la muestra universitaria. No obstante, se trata
}

Revista Española de Investigación Criminológica

Artículo 1, Número 6 (2008) $\quad$ www.criminología.net

ISSN: 1696-9219 
En definitiva, existen ciertamente cuestiones metodológicas relevantes que impiden tener en cuenta la investigación realizada como un estudio completo de las actitudes punitivas de los españoles. Pero el propósito de la investigación era uno mucho más modesto: se trata de presentar un estudio piloto o exploratorio sobre dichas actitudes punitivas, que ha de ser obviamente complementado (para reafirmarlo, matizarlo o refutarlo) en un futuro.

\section{Resultados de la investigación y discusión.}

Sobre la base del cuestionario diseñado y su distribución a la muestra relatada, los resultados más relevantes de nuestra investigación son los siguientes:

\section{III.1. “Problematización” de la delincuencia.}

Tal y como las investigaciones comparadas han podido documentar, lo primero que debe destacarse es que los ciudadanos tienen una visión que podríamos denominar "problemática" de la delincuencia. Decimos "problemática" porque en definitiva se le atribuye a la delincuencia una dimensión mayor (tanto cuantitativa como cualitativamente) que la que en realidad presenta. Así, en particular los ciudadanos creen que:

- la delincuencia se encuentra en continuo aumento

- una buena parte de la delincuencia es delincuencia violenta

- la mayoría de delincuentes son reincidentes o habituales

también de un resultado que ha de ser analizado con cautela debido a las carencias metodológicas de este estudio paralelo.

Revista Española de Investigación Criminológica

Artículo 1, Número 6 (2008) $\quad$ www.criminología.net

ISSN: $1696-9219$ 
Todo ello se puede apreciar en los resultados a las siguientes preguntas que planteaba el cuestionario:

\section{Gráfico 1: Tasa de delincuencia}

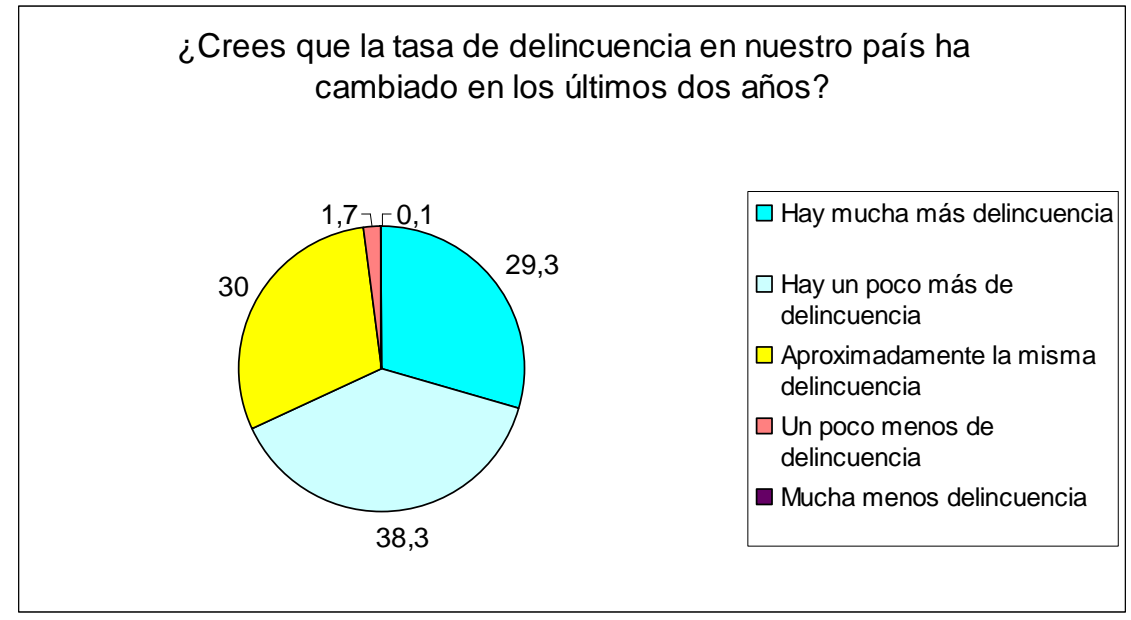

Como puede observarse, una gran mayoría de la muestra $(67,6 \%)$ cree que la delincuencia se encuentra en aumento, cuando los datos de los que disponemos no parecen confirmar ese sentimiento de "avalancha incontrolada de delitos"10.

Otro gráfico relevante es el que hace referencia al porcentaje de delitos que los ciudadanos creen que implican violencia o intimidación sobre las personas:

\footnotetext{
${ }^{10}$ Ciertamente, en nuestro país, debido a la inexistencia de encuestas de victimación generales "fiables" (metodológicamente), es difícil dar una respuesta concluyente a la recurrente pregunta sobre el aumento o descenso de la delincuencia. Los datos oficiales de delincuencia "registrada" (datos policiales) indican que en los últimos años el número de "delitos" ha descendido ligeramente, mientras las infracciones que aumentan son las "faltas" (vid. GARCÍA/PÉREZ, 2005:25 y ss.). Por lo que se refiere a encuestas de victimación realizadas en ámbitos geográficos concretos, cabe destacar que los datos de las encuestas de victimación realizadas en Málaga sugieren que no ha habido un aumento de la delincuencia (vid. GARCÍA/PERÉZ/BENÍTEZ, 2006:47 y ss.). Por su parte, los datos de las encuestas de victimación realizadas en Cataluña muestran un aumento de la delincuencia entre los años 1999 a 2003, pero desde entonces y hasta el 2005 (último dato disponible), estabilización e incluso un pequeño descenso en 2005 de la delincuencia (vid. ESPC, 2006 accesible en http://www.gencat.net/interior/docs/int_espc06.htm ).
}

Revista Española de Investigación Criminológica

Artículo 1, Número 6 (2008) $\quad$ www.criminología.net

ISSN: 1696-9219 


\section{Gráfico 2: tasa de delincuencia violenta}

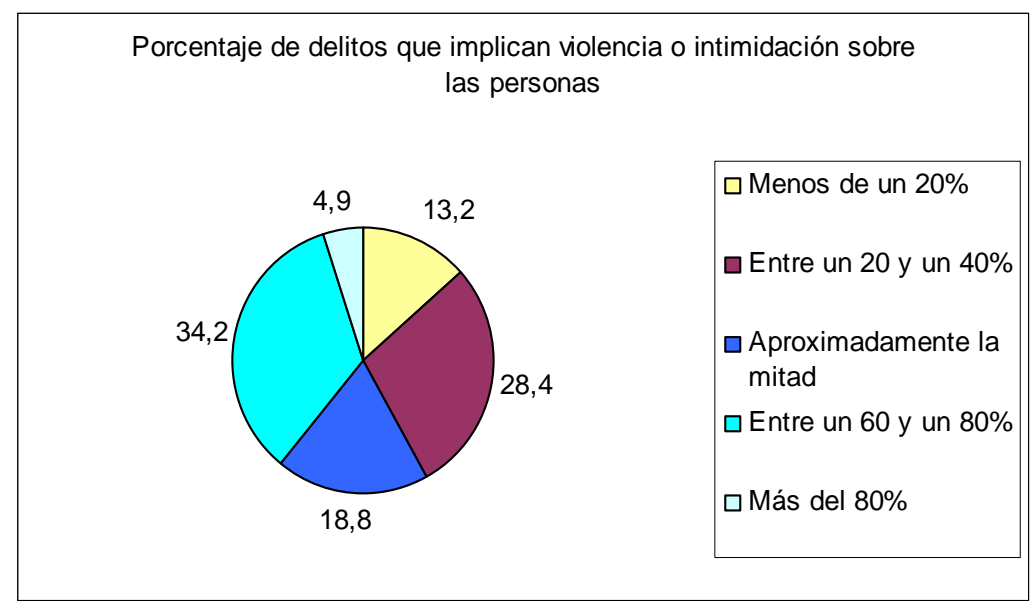

Como puede apreciarse la mayoría de encuestados $(57,9 \%)$ creen que una buena parte de los delitos (la mitad o más, destacando que la opción mayoritaria -un 34,2\%cree que entre un 60 y un $80 \%$ de los delitos son violentos) implican de hecho delincuencia violenta. Sin embargo todos los datos de que disponemos nos indican que esta cifra es mucho menor ${ }^{11}$.

Por último, otro dato relevante a la hora de hablar de "problematización" de la delincuencia por parte de los ciudadanos hace referencia al porcentaje de delitos que se creen cometidos por "profesionales de la delincuencia" (reincidentes o habituales):

\footnotetext{
${ }^{11}$ Por ejemplo, los datos policiales sobre delitos conocidos en el 2004 nos indican que existe un 5,83\% de delitos contra las personas (destacando en ellos los delitos de malos tratos -casi un $70 \%$ de estos delitos-), un $0,90 \%$ de delitos contra la libertad sexual y dentro del $80,11 \%$ de delitos contra el patrimonio, los delitos de robo con violencia/intimidación representan el 10,94\%, que a su vez es el 8,77\% del total de delitos. TOTAL $(5,83+0,90+8,77=)$ : el $15,5 \%$ de los delitos podrían considerarse que de alguna manera implican violencia o intimidación sobre las personas (Datos extraídos de GARCÍA/PÉREZ, 2005). La cifra que se puede extraer de algunas encuestas de victimación es mayor, pero en todo caso bastante inferior a la creencia ciudadana (según los datos de la ESPC, 2006; un 28\% de la victimación reconocida corresponde a hechos que implican violencia o intimidación sobre las personas).
}

Revista Española de Investigación Criminológica

Artículo 1, Número 6 (2008) $\quad$ www.criminología.net

ISSN: 1696-9219 


\section{Gráfico 3: tasa de delincuentes reincidentes / habituales}

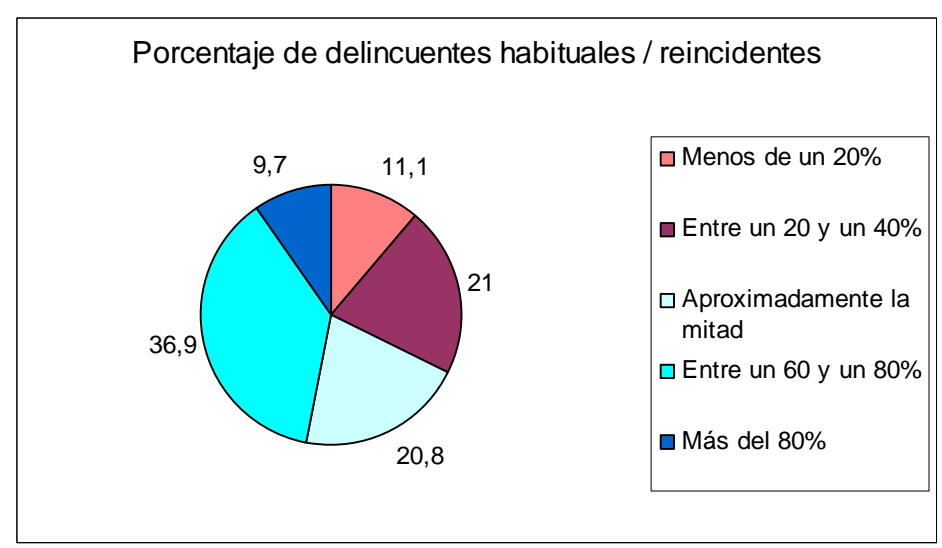

Una gran mayoría pues de "delincuencia profesional" (el 67,4\% de los encuestados creen que al menos la mitad de los delincuentes son reincidentes o habituales) es la que los encuestados creen que existe. Otra creencia que los datos de los que disponemos no parecen confirmar ${ }^{12}$.

En resumen, de los resultados a estas tres preguntas del cuestionario se puede deducir que el ciudadano cree que cada vez hay más delincuencia, que ésta es en buena parte violenta y obra de "profesionales". Sin duda un panorama bastante sombrío.

\section{III.2. Benevolencia del sistema penal.}

Otro dato fundamental que emerge de nuestra investigación, y que también ha sido sistemáticamente documentado en estudios comparados, es que los ciudadanos creen que el sistema penal trata con demasiada benevolencia a los delincuentes. En particular, los ciudadanos:

\footnotetext{
${ }^{12}$ Este es un dato que, de nuevo, es difícil de obtener en nuestro país. En las estadísticas judiciales del INE (que parecen presentar algunas carencias metodológicas) existen datos sobre reincidencia que por ejemplo señalan que en el 2003 para 120.000 "delitos apreciados", se contabilizan 25.400 reincidentes (algo más del 21\%). Más fiables, aunque provenientes de una muestra representativa limitada geográficamente, son los datos de reincidencia de un estudio sobre condenas judiciales en los Juzgados de lo Penal de Barcelona (CID/LARRAURI, coords., 2002:30 y ss.): los datos de este estudio muestran que de cada 100 procesados 70,5 no tienen antecedentes vivos (58 con expediente totalmente limpio, 8 con antecedentes cancelables, 3,5 con antecedentes posteriores, y 1 con antecedentes cancelables y posteriores), y de los 29,5 que sí tienen antecedentes, 10 son delincuentes habituales, 10 reincidentes no habituales y 9,5 no reincidentes). En todo caso, como puede verse los resultados no llegan ni de lejos a lo que la mayoría de encuestados señaló como delincuencia realizada por reincidentes o habituales (la mitad de la delincuencia).
}

Revista Española de Investigación Criminológica

Artículo 1, Número 6 (2008) $\quad$ www.criminología.net

ISSN: $1696-9219$ 
- creen que las penas impuestas a los delincuentes son, en general, blandas

- creen que hay una gran diferencia entre las penas efectivamente aplicadas por los jueces penales y las que éstos deberían imponer

- creen que las condenas no se cumplen, ni de lejos, en su totalidad

Todo ello se puede apreciar con nitidez en los resultados a las siguientes preguntas que planteaba la encuesta:

\section{Gráfico 4: benevolencia / severidad de las penas impuestas}

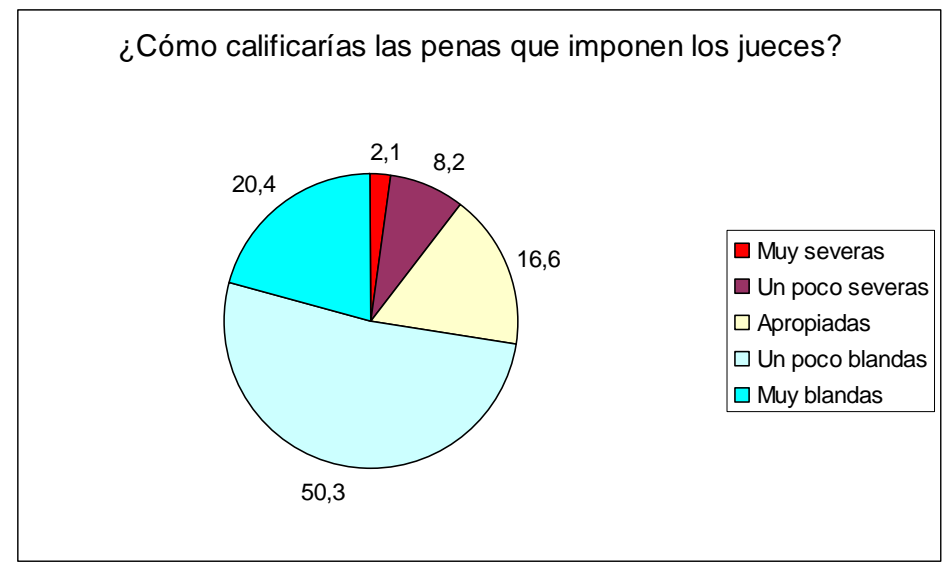

Una gran mayoría de los encuestados $(70,7 \%)$ cree que, en definitiva, las penas impuestas por los jueces son blandas (de hecho, para un 20,4\% son "muy blandas").

Ello se ve confirmado cuando preguntamos al ciudadano la pena que creen que los jueces aplican en un caso concreto, y a continuación la pena que ellos creen que los jueces deberían imponer en ese mismo supuesto. 
Gráficos 5 y 6: diferencia entre la pena que se cree que imponen los jueces y la pena que éstos deberían imponer (en un caso de violación)
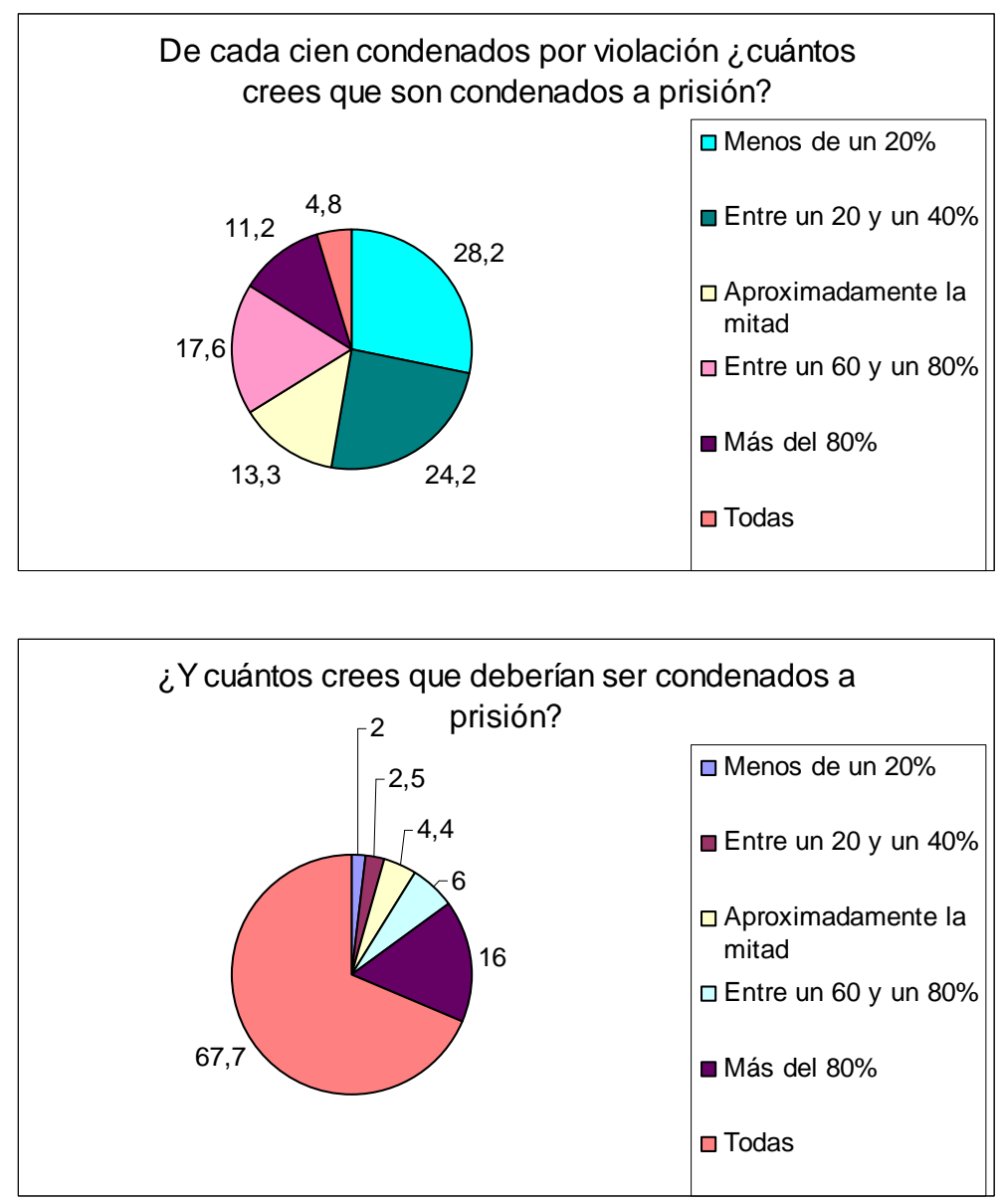

Como puede observarse existe una diferencia muy relevante entre el porcentaje de delincuentes que los ciudadanos creen que son condenados por el juez a pena de prisión por cometer un delito de violación (más de la mitad de los encuestados creen que dicho porcentaje no llega ni a la mitad), y el que los mismos ciudadanos creen que deberían ser enviados a prisión (un $67,7 \%$ de la muestra indica que todos los "violadores" deberían recibir una pena de prisión, mientras que sólo un 4,8\% de los encuestados creen que efectivamente los jueces imponen siempre pena de prisión por la comisión de un delito de violación). Ello indica claramente que los ciudadanos creen que existe una gran discrepancia entre las penas impuestas en la realidad por los jueces y las que ellos mismos impondrían en el mismo caso. 
Por último, la imagen ciudadana de una justicia penal blanda ante la delincuencia se completa con la pregunta relativa al cumplimiento efectivo de la pena de prisión:

\section{Gráfico 7: cumplimiento efectivo de la pena de prisión}

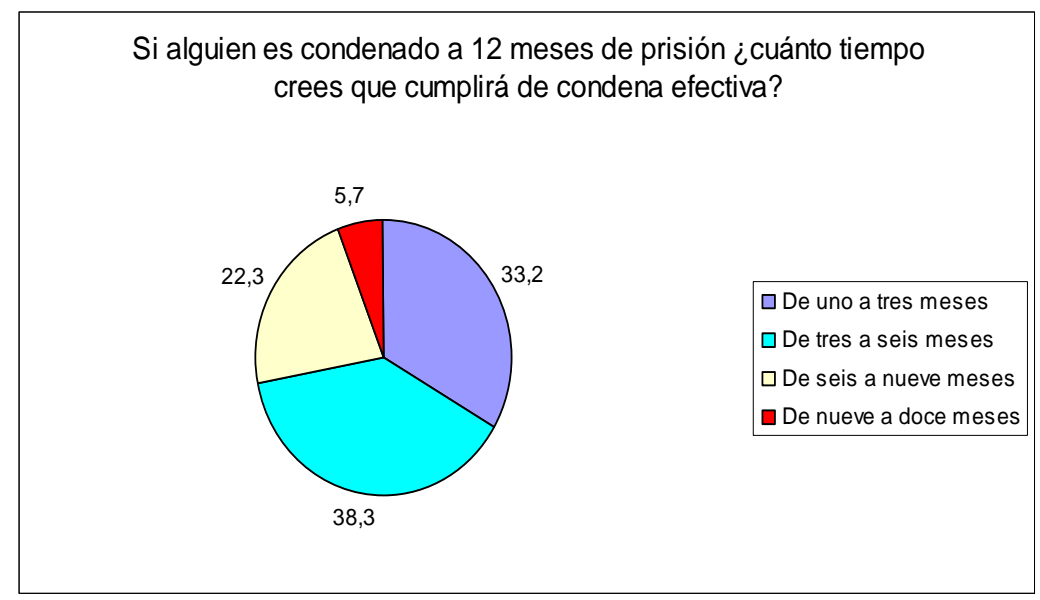

Como puede observarse, una amplia mayoría $(71,5 \%)$ cree que la pena efectiva de prisión cumplida no llega ni a la mitad de la pena impuesta. Sin embargo, sabemos que la realidad es muy distinta ${ }^{13}$.

En definitiva, un panorama bastante desolador, y más si se toma en conjunto todo lo hasta aquí analizado: para el ciudadano la delincuencia es cada vez un problema más serio y acuciante y el sistema penal lejos de reaccionar con presteza y contundencia impone penas blandas y que no se cumplen de forma adecuada. Todo ello podría hacernos pensar que existe una extendida actitud punitiva en la población, hastiada de la flagrante contradicción entre la importancia del problema (delincuencia) y la decepcionante respuesta del sistema penal ante ella. Sin embargo, según los datos de nuestra investigación que a continuación expondremos, la realidad es bien distinta.

\footnotetext{
${ }^{13}$ La clave aquí es que el Código Penal de 1995 derogó el principal beneficio penitenciario que existía (la redención de penas por el trabajo), lo cual ha situado en la práctica el cumplimiento efectivo de la pena muy cercano a la pena impuesta judicialmente. A ello ha contribuido también la reducción de los porcentajes de concesión de la libertad condicional y el tercer grado (vid. CID, 2005 y 2007).
}

Revista Española de Investigación Criminológica

Artículo 1, Número 6 (2008) $\quad$ www.criminología.net

ISSN: $1696-9219$ 


\section{III.3. El "mito del punitivismo ciudadano".}

Como decíamos, los resultados anteriores podrían hacernos sospechar que los ciudadanos mostrarían una actitud muy punitiva cuando fuesen preguntados por la pena aplicable a un caso concreto (técnica del "caso escenario"), ya que si piensan que la delincuencia es un fenómeno mucho más problemático de lo que en realidad es, y además creen que recibe un trato demasiado benévolo por parte de la justicia penal, no sería de extrañar que fueran partidarios de penas muy duras para todo tipo de delincuencia.

Sin embargo, los resultados de nuestra investigación son contrarios a esta hipótesis: no existe en la muestra una actitud punitiva destacable. Más bien al contrario. Según veremos a continuación, los encuestados:

- imponen en todos los casos escenario presentados penas que se encuentran por debajo (o incluso muy por debajo) de la pena en realidad impuesta por los jueces en casos similares

- manifiestan un amplio apoyo a las penas alternativas a la prisión

- manifiestan igualmente un amplio apoyo a la óptica rehabilitadora en el castigo

- tienen una visión más bien "social" o "estructural” de la delincuencia

En definitiva, estos resultados parecerían confirmar el "mito del punitivismo ciudadano". Veámoslo detenidamente analizando las cuatro cuestiones mencionadas anteriormente. 
III.3.1. Penas aplicadas en los “casos escenario”.

En la encuesta se planteaban cuatro casos escenario correspondientes a supuestos de criminalidad de gravedad media, pues son estos casos los que ponen realmente a prueba la elección ciudadana entre prisión y otras penas. Veamos los resultados por caso escenario:

a) Robo en vivienda por parte de reincidente ${ }^{14}$

\begin{tabular}{|l|l|}
$\begin{array}{c}\text { Pena para Caso Escenario 1: robo en domicilio por parte de } \\
\text { reincidente }\end{array}$ \\
$\begin{array}{l}\text { Prisión } \\
\text { Suspensión Prisión } \\
\square \text { Multa (1500-3000 euros) } \\
\square \text { Suspensión Vigilada } \\
\square \text { TBC } \\
\square \text { Control Electrónico } \\
\square \text { Reparación } \\
\square \text { Otras penas }\end{array}$ \\
\hline 31,5
\end{tabular}

Como puede observarse, destacan como opciones preferidas por los encuestados la reparación del daño, la pena de Trabajo en Beneficio de la Comunidad (TBC) y la pena de multa, siendo la prisión la cuarta opción escogida, con algo más de una cuarta parte de la muestra $(28,4 \%)^{15}$. Si tenemos en cuenta que por las circunstancias del caso planteado (robo con fuerza en casa habitada cometido por un reincidente), el marco de pena que fija nuestro actual Código Penal se situaría entre 3 años y 6 meses a 5 años (por aplicación de los arts. 241 y $66.13^{\mathrm{a}} \mathrm{CP}$ ), el juez penal impondría con casi total seguridad en nuestro caso una pena de prisión de obligado cumplimiento. Una pena, en suma, que sólo una minoría $(28,4 \%)$ de los encuestados cree la pena apropiada. Y además una pena de prisión que supera en mucho en cuanto a su duración, la estimada adecuada para el caso por la gran mayoría de los encuestados.

\footnotetext{
${ }^{14}$ Los porcentajes en los cuatro casos escenario no suman 100 porque se daba la opción al encuestado de escoger más de una pena.

${ }^{15}$ La siguiente pregunta de la encuesta pedía a aquéllos que habían escogido la prisión como la pena adecuada para el caso, que detallasen su duración. La mayoría (el 62,5\%) impuso una pena de prisión de entre 1 mes y 1 año de prisión. Sólo el 17,7\% de la muestra estimó adecuada una pena de prisión de más de dos años.
}

Revista Española de Investigación Criminológica

Artículo 1, Número 6 (2008) $\quad$ www.criminología.net

ISSN: $1696-9219$ 
b) Conducción bajo la influencia de bebidas alcohólicas (que provoca accidente con herido leve y daños materiales)

\begin{tabular}{|c|c|}
\hline \multicolumn{2}{|c|}{$\begin{array}{l}\text { Pena para Caso Escenario 2: conducción bajo efectos } \\
\text { alcohol (+accidente leve) }\end{array}$} \\
\hline 57,8 & 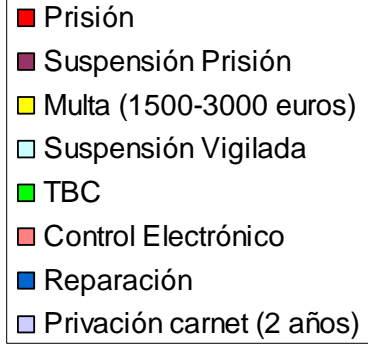 \\
\hline
\end{tabular}

De nuevo, la prisión no es ni mucho menos la opción preferida por los encuestados $^{16}$, a pesar de que una de las últimas modificaciones del Código Penal (LO 15/2003), la introdujera como pena principal (opcional) para el delito del art. 379 CP, y la recentísima reforma del Código Penal (Ley Orgánica 15/2007) deje claro que el camino que parece preferir nuestro legislador en materia de "delincuencia vial" sea el de castigar este tipo de delitos con la pena de prisión ${ }^{17}$.

\footnotetext{
${ }^{16} \mathrm{Y}$ por lo que se refiere a su duración, de nuevo una relevante mayoría (65\%) estima adecuada una pena de prisión de entre 1 mes y 1 año.

${ }^{17}$ No obstante, éste es un ámbito en el que la pena que declara la ley y la finalmente impuesta por el juez puede variar significativamente, porque según decimos en esta clase de delitos la pena de prisión normalmente es pena principal pero opcional. Y la experiencia práctica nos dice que la gran mayoría de condenas en estos casos consisten finalmente en la privación temporal del permiso de conducir y la imposición de una multa. Estamos así ante un supuesto que podríamos denominar gráficamente de "pena simbólica", ya que el legislador parece estar interesado en que la ley penal explicite claramente que es un delito que acarrea pena de prisión (probablemente para lanzar una fuerte advertencia a los ciudadanos), pero ésta no es posteriormente ni mucho menos la pena aplicada por la comisión del delito. La recentísima reforma del Código Penal (LO 15/2007) en materia de delitos de tráfico parece seguir claramente esta senda (vid. por ejemplo la entrevista con Bartolomé Vargas -Fiscal de Seguridad Vialaparecida en el diario EL PAÍS, de 5 de octubre de 2007, en la que declara que por la comisión de los nuevos delitos, a pesar de estar castigados con pena de prisión, casi nadie cumplirá efectivamente una pena de prisión). Todo ello plantea la cuestión siguiente: ciertamente en relación con el Código Penal que se decanta de forma principal por la pena de prisión como pena adecuada para el delito de conducción bajo la influencia de bebidas alcohólicas, los ciudadanos muestran una actitud mucho menos punitiva, pero si ese porcentaje se compara con la ejecución real de penas de prisión en estos delitos resulta que es mucho mayor. A mi entender, aunque esto es cierto lo relevante es que la mayoría de ciudadanos no apoya en primer término el castigo de ese delito con la pena de prisión.
}

Revista Española de Investigación Criminológica

Artículo 1, Número 6 (2008) $\quad$ www.criminología.net

ISSN: $1696-9219$ 
c) Violencia de Género habitual (con resultado lesivo leve)

$\begin{aligned} & \text { Pena para Caso Escenario 3: Violencia de Género } \\ & \text { habitual (falta de lesiones) }\end{aligned}$
$\begin{aligned} & \square \text { Prisión } \\ & \square \text { Suspensión Prisión } \\ & \square \text { Multa (1500-3000 euros) } \\ & \square \text { Suspensión Rehabilitadora } \\ & \square \text { TBC } \\ & \square \text { Control Electrónico } \\ & \square \text { Reparación } \\ & \square \text { Otras penas }\end{aligned}$

Destaca en este caso como pena preferida (por la mitad de la muestra) la suspensión de la pena con la condición de someterse a un programa de tratamiento de agresores domésticos. En segundo lugar se sitúa la pena de prisión $(37,8 \%)$, con el porcentaje más alto de todos los casos escenario planteados ${ }^{18}$. Ello sugiere que las campañas de sensibilización ciudadana llevadas a cabo en los últimos años que destacan la gravedad de la conducta maltratadora han calado en nuestra juventud ${ }^{19}$.

d) Tráfico de drogas (de menor entidad por parte de un adicto)

\begin{tabular}{|l|l|} 
Pena para Caso Escenario 4: Tráfico de Drogas \\
("trapicheo de adicto")
\end{tabular}

De nuevo, destaca con mucho como pena escogida (63,5\% de la muestra) la suspensión de la prisión con obligación de someterse a un tratamiento de

\footnotetext{
${ }^{18}$ Por otra parte, aunque de nuevo una mayoría $(60,1 \%)$ elige una pena de prisión de entre 1 mes y 1 año, se eleva al 32,2\% el porcentaje de la muestra partidaria de una pena de prisión de más de dos años.

${ }_{19}$ También destaca entre las penas el porcentaje relevante del control electrónico $(24,2 \%)$, muy superior al de los restantes casos-escenario, lo cual sugiere que los ciudadanos tienen claro que este tipo de delincuencia plantea un importante problema de reincidencia futura y por ello hay que esforzarse particularmente en el control del delincuente.
}

Revista Española de Investigación Criminológica

Artículo 1, Número 6 (2008) $\quad$ www.criminología.net

ISSN: $1696-9219$ 
deshabituación, lo cual indica que el encuestado tiene claro que este tipo de delincuencia tiene una etiología muy marcada que es lo que hay que procurar solventar, más allá del castigo de la conducta. De hecho, éste es el caso escenario en el que existe un menor porcentaje de elección de la pena de prisión $(18 \%)^{20}$, a pesar de que paradójicamente es aquél que el Código Penal sanciona más duramente ${ }^{21}$.

En resumen, en todos los casos escenario la prisión no es la opción mayoritariamente elegida por los encuestados, lo que vendría a confirmar el "mito del punitivismo ciudadano", ya que se atribuye a éste una actitud punitiva que por lo menos nuestra muestra desmiente.

\section{III.3.2. Amplio apoyo a las penas alternativas a la prisión.}

Otro dato en la misma línea nos lo proporcionan las preguntas incluidas en el cuestionario que trataban de evaluar el apoyo ciudadano de las penas alternativas a la prisión, ya que según veremos a continuación puede apreciarse un amplio apoyo ciudadano a este tipo de penas.

En primer lugar, los datos de los casos escenario anteriormente detallados ya confirman esta visión ciudadana positiva de las penas alternativas a la prisión, pues según hemos visto en todos ellos la sanción (o sanciones) penal preferida es siempre una pena alternativa a la prisión, especialmente cuando ésta es contemplada como una pena con contenido rehabilitador.

En segundo lugar, en nuestra investigación había dos preguntas dirigidas específicamente a valorar el apoyo de las penas alternativas a la prisión. En la primera de ellas se preguntaba al encuestado si estaría dispuesto a aplicar una pena alternativa a

\footnotetext{
${ }^{20}$ Quizás éste sí es un dato en el que la muestra escogida (jóvenes universitarios) marca una diferencia relevante. Por otra parte, hay que destacar que sin embargo, la minoría que escoge prisión parece más punitiva que en el resto de casos escenario (baja al 50,8\% el porcentaje de encuestados que sitúan la prisión entre 1 mes y 1 año).

${ }^{21}$ El marco de pena fijado por el art. 368 CP para el tráfico de drogas en el caso de tratarse de cocaína es de 3 a 9 años de prisión, aunque ciertamente la cuestión de la drogodependencia del imputado podría impedir (depende de la pena finalmente impuesta) el ingreso en prisión, si se cumplen los requisitos del art. $87 \mathrm{CP}$.
}

Revista Española de Investigación Criminológica

Artículo 1, Número 6 (2008) $\quad$ www.criminología.net

ISSN: $1696-9219$ 
la prisión en el caso de un delincuente que tuviera antecedentes penales, pues sabemos que éste es un caso en el que los jueces penales son muy reacios a ello ${ }^{22}$ :

\section{Gráfico 8: pena alternativa a la prisión para delincuente con antecedentes}

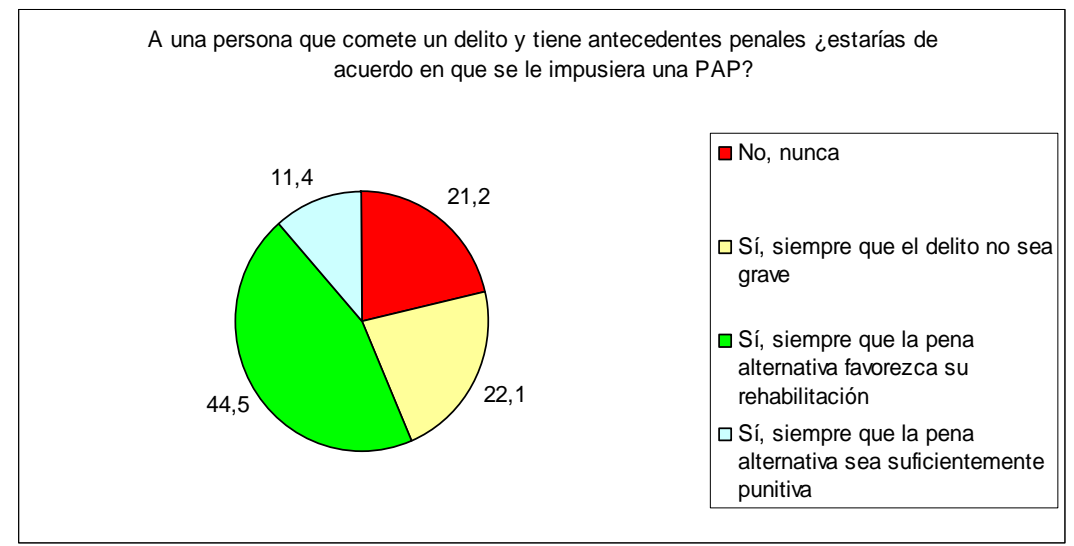

Como puede apreciarse, para la gran mayoría de la muestra (78\%) el hecho de que la persona tenga antecedentes penales no tendría por qué impedir, tal y como sucede normalmente en la práctica penal, la imposición de una pena alternativa a la prisión.

La segunda pregunta iba dirigida a evaluar el apoyo de una pena alternativa a la prisión específica: la suspensión de la pena de prisión. Queríamos preguntar por esta pena alternativa en particular porque probablemente es aquélla que pueda ser más polémica o "mal vista" por la ciudadanía, al ser fácilmente presentable como un simple perdón de la pena ${ }^{23}$.

\footnotetext{
${ }^{22}$ Vid. datos del estudio sobre una muestra representativa de sentencias de los Juzgados Penales de Barcelona en CID/LARRAURI (coords., 2002:58)

${ }^{23}$ Así por ejemplo, en nuestra doctrina penal considera CEREZO (2004:37 y ss., 155 y ss.) que "La posibilidad de concesión, con carácter general, de la suspensión de la ejecución de las penas privativas de libertad de duración no superior a dos años (...) implica, a mi juicio, un grave menoscabo de las exigencias de la prevención general y de la reafirmación del ordenamiento jurídico en aras de la prevención especial".
}

Revista Española de Investigación Criminológica

Artículo 1, Número 6 (2008) $\quad$ www.criminología.net

ISSN: 1696-9219 


\section{Gráfico 9: valoración de la suspensión de la pena de prisión}

\begin{tabular}{|c|c|}
$\begin{array}{c}\text { A una persona que ha cometido un delito por primera vez (castigado con prisión) } \\
\text { ¿estarías de acuerdo en que se le suspendiera la pena con la condición de no } \\
\text { delinquir? }\end{array}$ \\
$\begin{array}{l}\square \text { No, nunca: a quien comete un } \\
\text { delito hay que aplicarle la pena } \\
\text { prevista } \\
\square \text { Sí, siempre que el delito no sea } \\
\text { grave } \\
\square \text { Sí, siempre que el delito no sea } \\
\text { grave y la suspensión implique } \\
\text { supervisión / control } \\
\text { Sí, siempre que la prisión sea } \\
\text { sustituida por multa o TBC }\end{array}$ \\
43,3
\end{tabular}

Como puede apreciarse, los datos vuelven a mostrarnos una opinión ciudadana muy favorable a la posibilidad de dejar en suspenso una pena de prisión (sólo el 15,4\% rechaza de plano tal posibilidad), aunque dejando claro que dicha suspensión debiera ser algo más que un simple "perdón" (el 43,3\% quiere que exista algún tipo de control o supervisión y el $21 \%$ aprueba la suspensión siempre que la prisión sea sustituida por otra pena).

En tercer lugar y último, en el cuestionario había otra pregunta cuyo resultado puede leerse en la misma línea de apoyo a las penas alternativas a la prisión:

\section{Gráfico 10: soluciones a la masificación carcelaria}

\begin{tabular}{|c|} 
¿Cuál crees que es la mejor manera de reducir la masificación en las \\
cárceles?
\end{tabular}

Revista Española de Investigación Criminológica 
Como puede apreciarse, una amplia mayoría (60,6\% de la muestra) está a favor de encontrar métodos alternativos de castigo a la prisión, aunque eso sí, más punitivos que la simple suspensión de la pena.

\section{III.3.3. Amplio apoyo a la óptica rehabilitadora.}

En la misma línea de refutación de una actitud punitiva extendida entre la población pueden leerse también los resultados de las preguntas del cuestionario que de una u otra forma muestran el gran apoyo del que goza la óptica rehabilitadora de la sanción penal.

Así, en primer lugar ya hemos visto como en los casos escenario y en las preguntas específicas sobre penas alternativas a la prisión se apoyan fundamentalmente aquellas penas que los miembros de la muestra contemplan con capacidad rehabilitadora, subrayando así que el castigo penal tiene que ir más allá de la pura represión de la conducta, tratando de hacer frente a las causas del delito y así de reinsertar a la persona en la sociedad.

Y en segundo lugar (y ya más específicamente), debemos subrayar que los resultados de nuestra investigación muestran que las personas creen en la rehabilitación, como un fin de la pena en general, e incluso más si se plantea como una "posibilidad vital" o derecho que el sistema penal debiera esforzarse en realizar:

\section{Gráfico 11: finalidad de las penas}

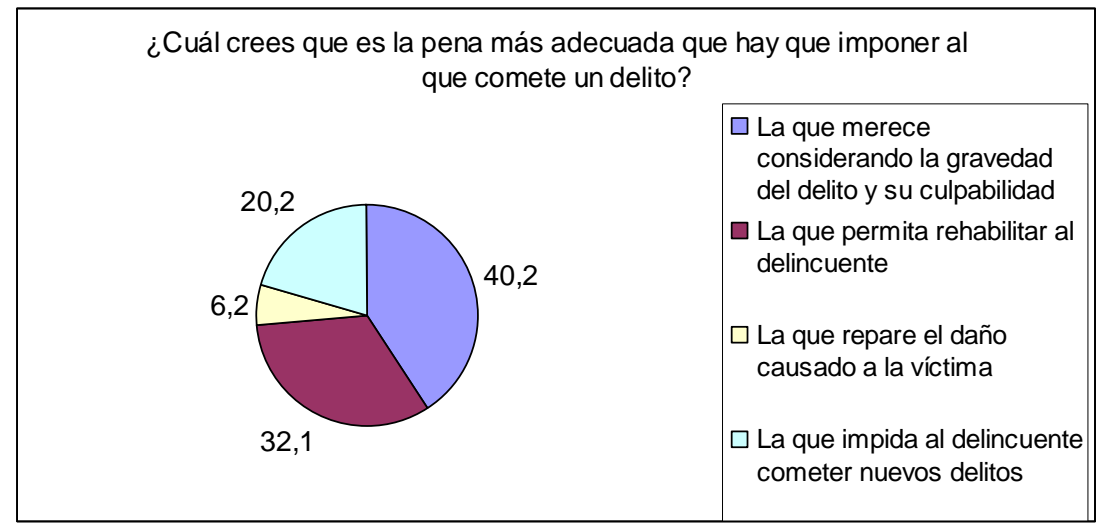

Revista Española de Investigación Criminológica 
Como puede observarse la rehabilitación es el fin primordial del castigo penal para casi un tercio de la muestra, ocupando así el segundo lugar en las preferencias. El porcentaje, no obstante, aumenta de forma significativa si se pregunta simplemente si la rehabilitación debe plantearse por el sistema penal como un objetivo a cumplir:

\section{Gráfico 12: creencia en la rehabilitación}

\begin{tabular}{|l|}
\hline Señala la afirmación con la que estés más de acuerdo \\
$\begin{array}{l}\begin{array}{l}\text { Es prácticamente imposible } \\
\text { cambiar a las personas (no } \\
\text { vale la pena esforzarse en } \\
\text { la rehabilitación) }\end{array} \\
\begin{array}{l}\text { Las personas cambian y } \\
\text { por tanto hay que perseguir } \\
\text { la rehabilitación de los } \\
\text { delincuentes (incluso } \\
\text { reincidentes) }\end{array}\end{array}$ \\
\hline 81,8
\end{tabular}

Como puede apreciarse una gran mayoría de los encuestados se muestra partidaria de la rehabilitación de los delincuentes (incluso reincidentes).

\section{III.3.4. Visión social o estructural de la delincuencia.}

Por último, un cuarto signo de que imputar a la ciudadanía una actitud punitiva sin matices es una equivocación, puede leerse también en los resultados a las preguntas del cuestionario que subrayan lo que podríamos denominar una visión "social o estructural" de la delincuencia. Esto es, una creencia en que la delincuencia es un fenómeno social que debe encontrar sus causas y remedios en toda una serie de factores sociales, y no, por el contrario, en la pura y simple voluntad y autonomía del delincuente.

Ello tendría que ver (como después apreciaremos) con las actitudes punitivas porque la hipótesis es que aquellos ciudadanos que ven la delincuencia como producto de la libre y voluntaria decisión individual del delincuente, creen que por ello se ha "ganado" la pena que el sistema estime conveniente. Por el contrario, aquellos 
ciudadanos que piensen que la delincuencia tiene que ver fundamentalmente con factores sociales, y que por tanto, de alguna forma, es una corresponsabilidad social, serán más partidarios de penas moderadas, ya que el factor clave que explicaría la delincuencia no ha de "cargarse" exclusivamente en el "debe" del delincuente.

Pues bien, los resultados de nuestra investigación muestran una población más bien favorable a la óptica social (versus individual) de la delincuencia. Así por ejemplo, preguntados específicamente por esta cuestión, los encuestados subrayan de forma muy mayoritaria el "origen social" de la delincuencia:

\section{Gráfico 13: origen/causas de la delincuencia}

\begin{tabular}{|l|l|}
\hline Señala la afirmación con la que estés más de acuerdo \\
$\begin{array}{l}\text { La delincuencia es } \\
\text { producto de una decisión } \\
\text { individual y racional de la } \\
\text { persona } \\
\text { La delincuencia es } \\
\text { producto de varios factores } \\
\text { sociales y económicos }\end{array}$ \\
$\begin{array}{l}\text { La delincuencia es } \\
\text { consecuencia de una } \\
\text { deficiencia o enfermedad } \\
\text { psíquica o adicción }\end{array}$ \\
\hline
\end{tabular}

Por otra parte, en la pregunta relativa a las causas del aumento de la delincuencia $^{24}$, también puede observarse esta visión social o estructural de la delincuencia:

\footnotetext{
${ }^{24}$ En concreto, se les preguntaba a aquellos encuestados que consideraban que la delincuencia había aumentado (según vimos, la gran mayoría), a qué causas atribuían dicho aumento.
}

Revista Española de Investigación Criminológica

Artículo 1, Número 6 (2008) $\quad$ www.criminología.net

ISSN: $1696-9219$ 


\section{Gráfico 14: causas del aumento de la delincuencia ${ }^{25}$}

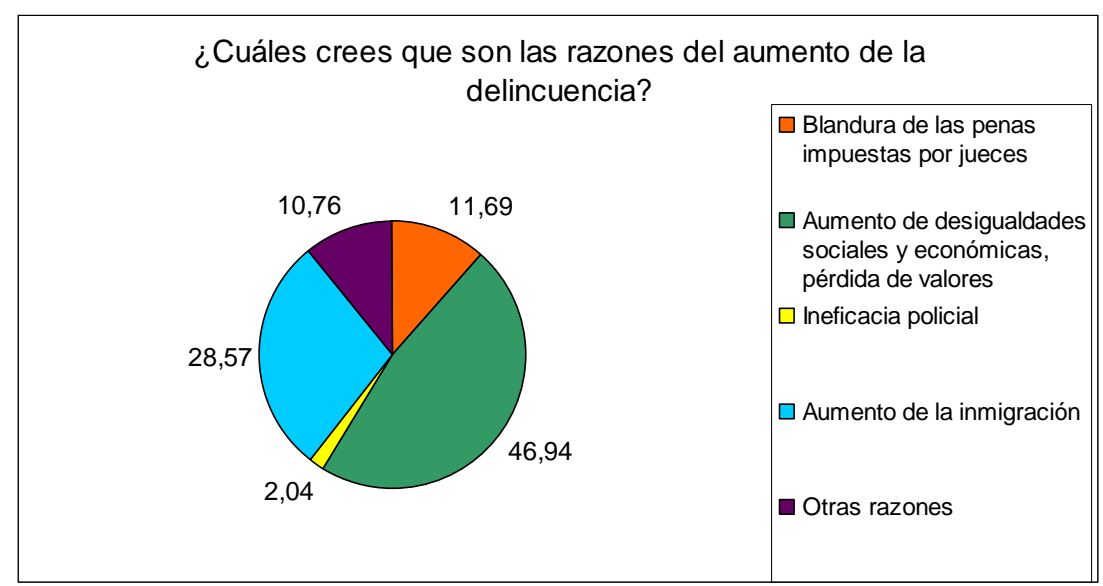

Por último, en las respuestas a la pregunta relativa a los medios eficaces para prevenir la delincuencia podemos apreciar la misma tónica:

\section{Gráfico 15: medios eficaces para prevenir la delincuencia}

\begin{tabular}{|c|c|}
\hline ¿Cuál de los siguientes mecanismos consideras más adecuado para \\
prevenir la delincuencia?
\end{tabular}

Como puede observarse, la respuesta mayoritaria liga la prevención de la delincuencia a un cambio en el modelo de sociedad (sus valores, la educación, etc.) y no, por ejemplo (y de forma destacable) al castigo, en particular al aumento de penas ${ }^{26}$.

En conclusión: el punitivismo ciudadano, según los resultados de nuestra investigación, parece ser un mito que no refleja la realidad.

\footnotetext{
${ }^{25}$ En este gráfico también destaca que a pesar de que la mayoría de encuestados cree, según vimos, que la delincuencia se encuentra en continuo aumento y que, por otra parte, las penas aplicadas por los jueces son blandas, no parecen vincular ambas cuestiones, pues la "blandura de las penas" sólo es señalada por una minoría $(11,69 \%)$ como causa del aumento de la delincuencia.

${ }^{26}$ La opción relativa a la imposición de penas más severas sólo fue señalada por el 10,7\% de la muestra, mientras que un $7,1 \%$ liga también prevención a sanción penal pero en el sentido inverso de considerar que el aumento del uso de penas alternativas a la prisión podría ser más eficaz.
}

Revista Española de Investigación Criminológica

Artículo 1, Número 6 (2008) $\quad$ www.criminología.net

ISSN: $1696-9219$ 


\section{III.4. “Causas” del punitivismo.}

Uno de los objetivos adicionales que nos planteábamos en la investigación era tratar de averiguar las "causas", o mejor dicho, las variables que podían estar en el origen, influir o "alimentar" el sentimiento punitivo entre la ciudadanía.

Para ello creamos una sub-muestra de la población total encuestada $(n=813)$ a la que denominamos "muestra punitivos" (MP), que se hallaba conformada por aquellas personas que habían contestado en los cuatro escenarios propuestos que la pena adecuada era la prisión $(n=37)^{27}$. Posteriormente, esta sub-muestra fue analizada en relación con toda una serie de variables que a priori identificamos como posiblemente relevantes, de acuerdo con la literatura comparada especializada sobre el tema. De hecho, las preguntas del cuestionario ya estaban directamente diseñadas para tener en cuenta toda esa serie de variables posiblemente relevantes a la hora de configurar un sentimiento más o menos punitivo. Se trata de variables que a efectos explicativos agruparemos en tres categorías:

- variables personales: hacen referencia a características personales como edad, sexo, ocupación laboral e ideología política.

- variables cognitivas: así denominadas porque hacen referencia al conocimiento o valoración que los encuestados tienen de ciertas cuestiones relacionadas con el funcionamiento del sistema penal (tasa de delincuencia, de delincuencia violenta, reincidentes, homicidios, valoración de las penas impuestas por los jueces, papel de jueces, policía, finalidad de las penas, etc.).

\footnotetext{
${ }^{27}$ Cabe destacar, de entrada, que la sub-muestra de punitivos es ciertamente pequeña (37 personas, esto es, un $4,6 \%$ del total de la muestra), lo cual confirma el punto tratado anteriormente relativo al mito de punitivismo ciudadano. De hecho, del total de la muestra un relevante $38,1 \% \%$ no considera adecuada la prisión en ninguno de los casos escenario propuestos, un $23,2 \%$ tan solo en un caso, un 18,7\% en la mitad de los casos y un $12,9 \%$ en tres de los cuatro casos-escenario.
}

Revista Española de Investigación Criminológica

Artículo 1, Número 6 (2008) $\quad$ www.criminología.net

ISSN: $1696-9219$ 
- variables emocionales (o creencias íntimas; MARUNA/KING, 2004:95): hacen referencia a cuestiones que tienen que ver con las creencias íntimas de las personas (en este sentido se habla también de variables emocionales), y que la literatura comparada especializada ha identificado como relevantes a la hora de formar una actitud punitiva o no (victimizacion previa, opinión sobre el origen o las causas de la delincuencia, creencia o no en la rehabilitación de los delincuentes y opinión sobre la situación social y económica del país).

Pues bien, después de cruzar la muestra de ciudadanos punitivos con todas las variables definidas, las que finalmente aparecieron como relevantes (utilizando la prueba de chi-cuadrado con el programa de análisis estadístico de datos SPSS) fueron las siguientes:

\section{a) Variables personales}

La única variable personal que apareció correlacionada (y de forma relevante) con la actitud punitiva fue la ideología política de la persona, en el sentido de que las personas que se auto-definían como de "Derechas" mostraban una actitud mucho más punitiva que el resto de encuestados. Y por otra parte, aquellas que se consideraban de "Izquierdas" tenían una actitud menos punitiva que la media.

Tabla 1: Ideología política y actitudes punitivas

\begin{tabular}{|l|c|c|c|c|}
\cline { 2 - 5 } \multicolumn{1}{c|}{} & \multicolumn{4}{c|}{ Ideología Política } \\
\cline { 2 - 5 } \multicolumn{1}{c|}{} & $\begin{array}{c}\text { Derecha / Centro- } \\
\text { Derecha }\end{array}$ & $\begin{array}{c}\text { Izquierda / Centro- } \\
\text { Izquierda }\end{array}$ & $\begin{array}{c}\text { Centro / } \\
\text { Apolítico }\end{array}$ & Total \\
\hline Punitivos & $10 \%(6)$ & $3,3 \%(19)$ & $6,9 \%(12)$ & $4,6 \%(37)$ \\
\hline No punitivos & $90 \%(54)$ & $96,7 \%(549)$ & $93,1 \%(162)$ & $765(95,4 \%)$ \\
\hline Total & $100 \%(60)$ & $100 \%(568)$ & $100 \%(174)$ & $100 \%(802)$ \\
\hline \multicolumn{4}{|l|}{$\mathrm{p}=0,033$}
\end{tabular}


La diferencia es aun más mayor si se procede a una división más marcada del abanico político $^{28}$. El resto de variables personales, según decimos, no mostró relevancia en la prueba estadística de chi-cuadrado ${ }^{29}$.

\section{b) Variables cognitivas}

Por lo que hace referencia a las variables relacionadas con el conocimiento o valoración de ciertos aspectos de la delincuencia y del funcionamiento del sistema penal, hemos de decir que las que aparecieron como relevantes en las pruebas de chi-cuadrado fueron, en primer lugar, la opinión sobre las penas impuestas por los jueces penales. En concreto, aquellas personas que piensan que las penas impuestas por los jueces son blandas son las que muestran una actitud más punitiva, tal y como refleja la siguiente tabla:

Tabla 2: Opinión sobre el rigor de las penas y actitudes punitivas

\begin{tabular}{|l|c|c|c|c|}
\cline { 2 - 5 } \multicolumn{1}{c|}{} & \multicolumn{3}{c|}{ Severidad / Benevolencia penas } & \multicolumn{1}{c|}{} \\
\cline { 2 - 5 } \multicolumn{1}{c|}{} & Severas & Apropiadas & Blandas & Total \\
\hline Punitivos & $0 \%(0)$ & $2,2 \%(3)$ & $5,95(34)$ & $4,6 \%(37)$ \\
\hline No punitivos & $100 \%(84)$ & $97,8 \%(132)$ & $94,1 \%(541)$ & $776(95,4 \%)$ \\
\hline Total & $100 \%(84)$ & $100 \%(135)$ & $100 \%(575)$ & $100 \%(813)$ \\
\hline \multicolumn{2}{|c}{$\mathrm{p}=0,019$}
\end{tabular}

En segundo lugar, también se mostró como relevante la opinión sobre la finalidad del castigo. En concreto, las personas que atribuyen a las penas unas finalidades, primordialmente, de puro castigo (retribución) o incapacitación del delincuente, son más punitivas que aquellas que consideran primariamente la rehabilitación del delincuente o la reparación del daño:

\footnotetext{
${ }^{28} \mathrm{Si}$ se tienen en cuenta sólo los que se consideran de "Derechas" el porcentaje de punitivos entre este grupo aumenta al 30,8\% ( $n=4)$, y en relación a los que se definen como de "Izquierdas", la ratio de punitivos baja al 2,6\% (n=9). En este caso la asociación estadística es aún más significativa $(\mathrm{s}=0,000)$, pero se basa en grupos más escasos.

${ }^{29}$ Los hombres mostraban una actitud ligeramente más punitiva que las mujeres (5\% punitivos vs. 4,3\%), pero no estadísticamente relevante. Y por lo que hace referencia a la situación laboral, los encuestados que declararon no trabajar (a parte de estudiar) tenían igualmente una actitud ligeramente más punitiva que los que contestaron que trabajaban (aun eventualmente) durante el curso (6\% punitivos vs. 4,9 \%), aunque igualmente se trata de una diferencia no relevante estadísticamente en la prueba de chi-cuadrado.
}

Revista Española de Investigación Criminológica

Artículo 1, Número 6 (2008) $\quad$ www.criminología.net

ISSN: 1696-9219 
Tabla 3: Finalidad del castigo y actitudes punitivas

\begin{tabular}{|l|c|c|c|}
\cline { 2 - 3 } \multicolumn{1}{c|}{} & \multicolumn{2}{c}{} & \multicolumn{1}{c}{} \\
\cline { 2 - 4 } \multicolumn{1}{c|}{} & Rinalidad de las penas & Total $^{30}$ \\
\hline Punitivos & $6,3 \%(31)$ & $\begin{array}{c}\text { Rehabilitación / } \\
\text { Reparación }\end{array}$ & $4,6 \%(37)$ \\
\hline No punitivos & $93,7 \%(460)$ & $1,9 \%(6)$ & $765(95,4 \%)$ \\
\hline Total & $100 \%(491)$ & $98,1 \%(305)$ & $100 \%(802)$ \\
\hline \multicolumn{2}{|c}{$\mathrm{p}=0,004$} & $100 \%(311)$ & \\
\hline
\end{tabular}

En tercer lugar, otra variable cognitiva destacada fue la opinión sobre los medios de prevención de la delincuencia. En concreto, la muestra de punitivos da mayor importancia a opciones como "aumentar los efectivos policiales y las penas" y "llevar a cabo una política de inmigración más restrictiva":

Tabla 4: Prevención de la delincuencia y actitudes punitivas (PAP: penas alternativas a la prisión)

\begin{tabular}{|l|c|c|c|c|c|c|}
\cline { 2 - 6 } \multicolumn{1}{c|}{} & \multicolumn{9}{c|}{ Prevención de la delincuencia } & \multirow{2}{*}{} \\
\cline { 2 - 6 } & $\begin{array}{c}\text { Aumentar } \\
\text { disciplina / } \\
\text { cambiar sociedad }\end{array}$ & $\begin{array}{c}\text { Mejorar } \\
\text { situación } \\
\text { económica }\end{array}$ & $\begin{array}{c}\text { Aumentar } \\
\text { penas / } \\
\text { policía }\end{array}$ & $\begin{array}{c}\text { Aumentar } \\
\text { uso PAP }\end{array}$ & $\begin{array}{c}\text { Política } \\
\text { inmigración } \\
\text { restrictiva }\end{array}$ & Total \\
\hline Punitivos & $3,3 \%(15)$ & $4,8 \%(5)$ & $10,5 \%(11)$ & $0 \%(0)$ & $7,8 \%(6)$ & $4,6 \%(37)$ \\
\hline No punitivos & $96,7 \%(446)$ & $95,2 \%(100)$ & $8,5 \%(94)$ & $100 \%(58)$ & $92,2 \%(71)$ & $769(95,4 \%)$ \\
\hline Total & $100 \%(461)$ & $100 \%(105)$ & $100 \%(105)$ & $100 \%(58)$ & $100 \%(77)$ & $100 \%(806)$ \\
\hline
\end{tabular}

La cuarta variable relevante hace referencia a la solución preferida por los encuestados a la masificación actual de las cárceles. Como se puede apreciar en la siguiente tabla la muestra de punitivos es más partidaria de la construcción de más prisiones, aun a costa de aumentar los impuestos o reducir el gasto en otras áreas. Por otra parte, dicho grupo se muestra también muy reacio a la posibilidad de aliviar la masificación carcelaria avanzando la libertad condicional de los delincuentes no violentos (con control y supervisión):

${ }^{30}$ Los porcentajes desagregados de punitivos respecto al fin del castigo son los son los siguientes: retribución $(6,1 \%)$, rehabilitación $(2,3 \%)$, reparación $(0 \%)$ e incapacitación $(6,7 \%)$.

Revista Española de Investigación Criminológica

Artículo 1, Número 6 (2008) $\quad$ www.criminología.net

ISSN: 1696-9219 
Tabla 5: Solución masificación cárceles y actitudes punitivas

\begin{tabular}{|l|c|c|c|c|}
\cline { 2 - 5 } \multicolumn{1}{c|}{} & \multicolumn{3}{c|}{ Solución masificación cárceles } & \multicolumn{1}{c|}{} \\
\cline { 2 - 5 } \multicolumn{1}{c|}{} & Nuevos castigos & $\begin{array}{c}\text { Avanzar libertad } \\
\text { condicional }\end{array}$ & $\begin{array}{c}\text { Construir más } \\
\text { prisiones }\end{array}$ & Total \\
\hline Punitivos & $5,3 \%(26)$ & $1 \%(2)$ & $8,8 \%(9)$ & $4,7 \%(37)$ \\
\hline No punitivos & $94,7 \%(467)$ & $99 \%(203)$ & $91,2 \%(93)$ & $763(95,3 \%)$ \\
\hline Total & $100 \%(493)$ & $100 \%(205)$ & $100 \%(102)$ & $100 \%(800)$ \\
\hline \multicolumn{2}{|c}{$\mathrm{p}=0,009$} &
\end{tabular}

Por último, también se mostró como relevante en las pruebas estadísticas un dato sorprendente: la experiencia previa sobre la prisión (ya sea como visitante o por cualquier otro motivo). En realidad, lo sorprendente es que dicha experiencia previa apareció correlacionada con una mayor actitud punitiva, cuando probablemente hubiéramos esperado la tendencia inversa:

Tabla 6: Estancia en prisión y actitudes punitivas

\begin{tabular}{|l|c|c|c|}
\cline { 2 - 4 } \multicolumn{1}{c|}{} & \multicolumn{2}{c}{} & \multicolumn{1}{c}{} \\
\cline { 2 - 4 } \multicolumn{1}{c|}{} & Sí & No & Total \\
\hline Punitivos & $10,4 \%(11)$ & $3,7 \%(26)$ & $4,6 \%(37)$ \\
\hline No punitivos & $89,6 \%(95)$ & $96,3 \%(676)$ & $771(95,4 \%)$ \\
\hline Total & $100 \%(106)$ & $100 \%(702)$ & $100 \%(808)$ \\
\hline \multicolumn{2}{|c}{} \\
\hline
\end{tabular}

En definitiva, como puede observarse, en el grupo que hemos definido como variables cognitivas algunos de los resultados obtenidos son hasta cierto punto lógicos, pues ya casan con una actitud más o menos punitiva (opinión sobre los medios de prevención delincuencia y sobre la solución a la masificación carcelaria). Son en este sentido resultados cuasi-tautológicos. Más interesantes son las otras correlaciones descubiertas: así, en primer lugar, la relación entre la opinión sobre el rigor de las penas y la actitud punitiva, pues ello mostraría que la imagen equivocada que los ciudadanos tienen del sistema penal (mejor dicho, la imagen sesgada que les trasmiten los medios de comunicación), en el sentido de su trato "benévolo" al delincuente, puede ser una fuente de "desasosiego" o preocupación, que a su vez genera un sentimiento punitivo como reacción a dicha pasividad o benevolencia del sistema penal. En segundo lugar, es destacable también la relación hallada entre actitudes punitivas y opinión sobre 
la finalidad del castigo, pues como veremos a continuación confirma uno de los hallazgos fundamentales de esta investigación: la creencia en la rehabilitación de los delincuentes es una "medicina" bastante eficaz contra las actitudes punitivas. En tercer lugar y por último, la correlación entre experiencia previa sobre la prisión y actitudes punitivas no parece encontrar una buena hipótesis explicativa $^{31}$.

\section{c) Variables emocionales}

Por último, por lo que se refiere a las variables emocionales lo primero que quisiéramos destacar es que el hecho de haber sido víctima de un delito no se mostró como relevante estadísticamente a la hora de conformar una actitud más o menos punitiva, lo cual confirma algunas investigaciones que ya han subrayado que imputar un sentimiento punitivo sin más a las víctimas de un delito es un error (vid. MARUNA/KING, 2004:92-93) ${ }^{32}$.

Tampoco mostró relevancia estadística alguna la pregunta diseñada para tratar de captar si la "ansiedad social y económica" tenía relación con las actitudes punitivas $^{33}$.

\footnotetext{
${ }^{31}$ Aquí hay que tener en cuenta que por el tipo de muestra seleccionada (población universitaria) puede afirmarse casi con toda seguridad que la experiencia en prisión de la que se trata es la de haber visitado alguna prisión. Y probablemente las prisiones españoles no concuerdan con la imagen popular de la prisión difundida en los medios de comunicación (principalmente la televisión, en la que el modelo de prisión parece ser el americano, con un control más férreo de los internos). En cuanto al resto de variables, y a pesar de que no mostraron una correlación relevante en la prueba de chi-cuadrado, vale la pena mencionar que la muestra de punitivos tiende a considerar que existe más delincuencia $(5,4 \%$ vs. $2,9 \%$ de los que consideran que la delincuencia no ha aumentado), que se cometen más homicidios ( $8,4 \%$ respecto de los que creen que hay más de cinco homicidios al día en nuestro país vs. 4,1 de los que consideran que se cometen menos de cinco al día), que la delincuencia es más violenta (6\% de los que creen que el $60 \%$ o más de la delincuencia implica violencia o intimidación sobre las personas vs. 3,7\% de los que creen que dicho porcentaje es menor del 60\%) y que existe un mayor porcentaje de delincuentes reincidentes o habituales $(7,6 \%$ respecto de los que creen que más del $80 \%$ de los delincuentes son reincidentes o habituales vs. $1,1 \%$ de los que creen que ese porcentaje no llega al 20\%).

${ }^{32}$ De hecho, y aunque ya hemos dicho que sin relevancia estadística, vale la pena remarcar que la tendencia es que las víctimas son menos punitivas ( $2,6 \%$ de punitivos en el grupo de víctimas $-\mathrm{n}=232$ - vs. $5,4 \%$ en el grupo de no víctimas). Éste parece ser también un tema en el que los resultados pueden estar afectados por la muestra seleccionada para la investigación (población universitaria), ya que algunos estudios han puesto de manifiesto que aunque los jóvenes son el estrato de población más victimizado, son también a la vez los que menor afectación subjetiva declaran haber sufrido por el delito (vid. ESPC, 2006, págs. 13, 17-18, accesible en http://www.gencat.net/interior/docs/InformeESPC2006.pdf ).

${ }^{33}$ De hecho, al contrario de lo esperado, aquellos que opinaban que la situación social y económica es mejor actualmente eran los que tenían una actitud más punitiva (6,7\% de este grupo formaban parte de la
}

Revista Española de Investigación Criminológica 
Dicho esto, las variables que sí mostraron relevancia estadística (y muy notable) fueron las relativas a la opinión sobre el origen o causas de la delincuencia y la creencia (o no) en la rehabilitación de los delincuentes. Ello confirma los resultados de algunas investigaciones comparadas que ya han subrayado la gran importancia de estas variables emocionales en la explicación de las actitudes punitivas (vid. MARUNA/KING, 2004:95 у 99$)^{34}$.

En concreto, por lo que hace referencia al origen o causas de la delincuencia puede apreciarse que aquellas personas que ven el delito como consecuencia de una decisión libre y racional del delincuente son mucho más punitivos que los que consideran la delincuencia como el producto de diversos factores sociales y económicos:

Tabla 7: origen de la delincuencia y actitudes punitivas

\begin{tabular}{|l|c|c|c|c|}
\cline { 2 - 4 } \multicolumn{1}{c|}{} & \multicolumn{3}{c|}{ Origen / Causas delincuencia } & \multirow{2}{*}{} \\
\cline { 2 - 5 } \multicolumn{1}{c|}{} & $\begin{array}{c}\text { Decisión libre y } \\
\text { racional }\end{array}$ & $\begin{array}{c}\text { Producto de factores } \\
\text { socio-económicos }\end{array}$ & $\begin{array}{c}\text { Deficiencia psíquica } \\
\text { /adicción }\end{array}$ & Total \\
\hline Punitivos & $9,8 \%(19)$ & $2,7 \%(16)$ & $14,3 \%(2)$ & $4,6 \%(37)$ \\
\hline No punitivos & $90,2 \%(175)$ & $97,3 \%(578)$ & $85,7 \%(12)$ & $765(95,4 \%)$ \\
\hline Total & $100 \%(194)$ & $100 \%(594)$ & $100 \%(14)$ & $100 \%(802)$ \\
\hline \multicolumn{2}{|c}{$\mathrm{p}=0,000$}
\end{tabular}

Y en segundo lugar, por lo que hace referencia a la creencia o no en la rehabilitación de los delincuentes, se observa que la muestra de punitivos está conformada por personas que tienen menos fe en la rehabilitación:

muestra de punitivos, vs. 4,6\% del grupo "la situación social y económica es cada vez peor" y $1,5 \%$ del grupo "la situación social y económica no ha cambiado y se puede considerar aceptable").

34 En concreto, las hipótesis son las dos siguientes: primera (por lo que se refiere a las causas de la delincuencia), la respuesta que damos a la delincuencia tiene mucho que ver con las causas a las que la atribuimos. Segunda, si creemos que el delincuente es una persona permanente e inherentemente "mala" (

Revista Española de Investigación Criminológica

Artículo 1, Número 6 (2008) $\quad$ www.criminología.net

ISSN: $1696-9219$ 
Tabla 8: creencia en la rehabilitación y actitudes punitivas

\begin{tabular}{|l|c|c|c|}
\cline { 2 - 4 } \multicolumn{1}{c|}{} & \multicolumn{2}{c|}{ Creencia en la Rehabilitación } & \\
\cline { 2 - 4 } \multicolumn{1}{c|}{} & $\begin{array}{c}\text { NO: No se puede cambiar } \\
\text { a las personas }\end{array}$ & $\begin{array}{c}\text { Sí: Las personas } \\
\text { pueden cambiar }\end{array}$ & Total \\
\hline Punitivos & $11,7 \%(16)$ & $3,2 \%(21)$ & $4,6 \%(37)$ \\
\hline No punitivos & $88,3 \%(121)$ & $96,8 \%(644)$ & $765(95,4 \%)$ \\
\hline Total & $100 \%(137)$ & $100 \%(665)$ & $100 \%(802)$ \\
\hline \multicolumn{2}{|c}{$\mathrm{p}=0,000$} &
\end{tabular}

Ello es coherente con los resultados ya mencionados sobre finalidad de las penas y actitudes punitivas.

Con todo ello podríamos trazar el perfil del "punitivo" como una persona de ideología política de Derechas (o centro-derecha), que atribuye al castigo una finalidad retributiva o incapacitadora, cree que las penas aplicadas por los jueces son blandas, que el mejor medio para prevenir la delincuencia es el aumento de los efectivos policiales y las penas (así como una política de inmigración restrictiva) y que la solución a la masificación carcelaria pasa simplemente por construir más cárceles. Por lo que se refiere a las causas de la delincuencia el "punitivo" cree que se trata básicamente de una opción de vida libremente escogida por el delincuente. Esta atribución de la delincuencia a la libre voluntad de la persona hace que, por otra parte, el "punitivo" tenga menos fe en la rehabilitación de los delincuentes.

Por contra, las personas que se definen ideológicamente como de "Izquierdas" y que creen, primero, que la delincuencia es un fenómeno que encuentra sus causas (y así su posible remedio) en la estructura social y económica del país, y segundo, en la rehabilitación de los delincuentes, son los que integrarían el grupo social menos punitivo.

\section{III.5. Inmigración y actitudes punitivas.}

Por último, otro de los objetivos de la investigación, en la misma línea de tratar de averiguar los factores que juegan a la hora de desarrollar una actitud más o menos punitiva, era analizar el rol que en este aspecto podía tener la variable "nacionalidad del delincuente" y en general la cuestión de la inmigración. Y es que, como es bien sabido,

\footnotetext{
${ }^{35}$ En el cuestionario la opción planteada decía lo siguiente "Las personas pueden cambiar y por tanto vale la pena intentar conseguir que los delincuentes, incluso los reincidentes, se rehabiliten para que se puedan reintegrar en la sociedad".
}

Revista Española de Investigación Criminológica

Artículo 1, Número 6 (2008) $\quad$ www.criminología.net

ISSN: $1696-9219$ 
en los últimos años el fenómeno de la inmigración ha alcanzado una dimensión que no había tenido antes en nuestro país, y ha tendido a ser relacionado de forma demasiado ligera y frecuente con la delincuencia (vid. criticando tal relación MEDINA, 2006 y RECHEA/FERNÁNDEZ/BENÍTEZ, 2004). Un objetivo adicional de la investigación era, por tanto, comprobar si esta vinculación que tan a menudo realizan algunos partidos políticos y medios de comunicación ha calado de algún modo en la población.

Para esta finalidad de la investigación desarrollamos dos cuestionarios paralelos que se distribuyeron aleatoriamente entre la muestra, de tal manera que prácticamente la mitad contestó el cuestionario A y la otra mitad el B. La única diferencia entre ambos cuestionarios es que la nacionalidad de los delincuentes en los cuatro escenarios variaba. En concreto, la distribución era la siguiente:

\begin{tabular}{|c|c|c|c|c|}
\cline { 2 - 5 } \multicolumn{1}{c|}{} & CASO ESCENARIO A & CASO ESCENARIO B & CASO ESCENARIO C & CASO ESCENARIO D \\
\hline MODELO A & español & colombiano & español & marroquí \\
\hline MODELO B & rumano & español & marroquí & español \\
\hline
\end{tabular}

En la siguiente tabla se muestran los porcentajes de encuestados que señalaron que la prisión era la pena adecuada para el caso escenario teniendo en cuenta la variable de la nacionalidad del delincuente (en función del cuestionario respondido):

Tabla 9: prisión en casos escenario según nacionalidad delincuente

\begin{tabular}{|l|c|c|c|c|}
\cline { 2 - 5 } \multicolumn{1}{c|}{} & CASO ESCENARIO A & CASO ESCENARIO B & CASO ESCENARIO C & CASO ESCENARIO D \\
\hline español & 28,9 & 23,4 & 35,8 & 15,6 \\
\hline extranjero & 28,5 & 27,4 & 40,6 & 20,6 \\
\hline
\end{tabular}

Como se puede apreciar, excepto en el primer caso escenario (robo en domicilio por parte de reincidente), en los demás supuestos existe una diferencia en el porcentaje de opción por la prisión, que en definitiva acaba imponiéndose más si el autor del delito es un extranjero. La diferencia es más marcada, llegando a los 5 puntos porcentuales, en los casos en los que el delincuente es un nacional de Marruecos.

Los resultados sugieren, por tanto, que sí parece existir una diferencia para los ciudadanos en el trato penal en función de la nacionalidad del delincuente, mostrando

Revista Española de Investigación Criminológica 
una actitud más punitiva en el caso de que éste sea extranjero, sobre todo si es marroquí, precisamente uno de los colectivos que más claramente ha sido vinculado por los medios de comunicación con la delincuencia. No obstante, en los análisis estadísticos (Chi-cuadrado) la única asociación significativa al 95\% ( $\mathrm{p}=0,05)$ que se detectó fue en el caso escenario del tráfico de drogas, con una mayor predisposición a la prisión cuando el "protagonista" de la pregunta es un ciudadano magrebí.

Al margen de los casos escenario modificados en lo que se refiere a la nacionalidad del delincuente, en el cuestionario había dos preguntas en las que diseñamos las posibles respuestas de manera que también nos pudieran dar algunas pistas sobre el rol que la inmigración tenía para el ciudadano en la conformación de actitudes más o menos punitivas.

La primera de ellas es una pregunta que ya hemos comentado al tratar las "causas" del punitivismo. En concreto, dentro de las variables cognitivas, la referida a los medios más eficaces para prevenir la delincuencia (vid. supra Tabla 4). Una de las posibles respuestas en referencia a los medios de prevención de la delincuencia apuntaba hacia el desarrollo de políticas de inmigración más restrictivas. Pues bien, los resultados de la tabla muestran que entre los que se decantaron por esta opción hay cerca del doble de punitivos que en la muestra genérica $(7,8 \%$ vs. $4,6 \%$ del total de la muestra).

La segunda pregunta diseñada para proporcionarnos pistas en el mismo sentido era la referida a las razones del aumento de la delincuencia (para aquellos que hubieran contestado que la delincuencia había aumentado en los dos últimos años: vid. resultados generales en Gráfico 14). Una de las posibles respuestas era directamente el "aumento de la inmigración" en nuestro país. Nuevamente, los resultados muestran que los que entre los que escogieron dicha opción hay cerca del doble de punitivos (7,8\% vs. 4,6\% del total de la muestra).

Por tanto, los resultados de estas dos preguntas diseñadas específicamente para avanzar sobre la cuestión relativa al rol de la inmigración (mejor dicho, la vinculación que con frecuencia se realiza entre inmigración y delincuencia) en la conformación de actitudes punitivas, sugieren que efectivamente el punitivismo podría venir siendo

Revista Española de Investigación Criminológica 
"alimentado" por una desconfianza hacia la inmigración al vincularla con la delincuencia. La hipótesis es que ello podría estar contribuyendo a un "alejamiento" hacia el delincuente al considerarlo perteneciente a un sector poblacional "extraño", lo cual bloquearía cualquier sentimiento de empatía o comprensión que pudieran limitar el castigo penal.

Por lo tanto, al perfil del "punitivo" anteriormente trazado habría que añadir que se trata además de una persona que vincula inmigración con delincuencia. En definitiva, una razón más para preocuparse por la vinculación tan ligera e indiscriminada que desde algunos sectores políticos y mediáticos se realiza entre inmigración y delincuencia.

\section{Conclusiones.}

Obviamente, como estudio piloto exploratorio hemos de ser muy cautos a la hora de extraer conclusiones de la investigación realizada, pues ya hemos subrayado las limitaciones metodológicas de nuestra muestra ${ }^{36}$. No obstante, lo que los resultados de nuestra investigación nos permiten decir es lo siguiente:

Primero. Tal y como las investigaciones comparadas han acreditado, aunque el conocimiento que los ciudadanos tienen del funcionamiento del sistema penal es bastante precario, lo que está claro es que tienden sistemáticamente a creer que vivimos en un periodo de aumento constante de la delincuencia ("problematización" del fenómeno), y que el sistema penal, y en particular los jueces, no reaccionan con firmeza ante esta situación. Existe así una creencia extendida en la benevolencia del sistema hacia el delincuente, al creer que las penas son mucho más blandas de las aplicadas realmente y que no se cumplen ni mucho menos en su totalidad.

Segundo: Aun así, los datos de nuestra investigación, en línea también con investigaciones comparadas, muestran que los ciudadanos no podrían definirse, ni

\footnotetext{
${ }^{36}$ A dichas limitaciones metodológicas "internas" habría que añadir los problemas que ya en sí plantea el estudio de las actitudes y sentimientos punitivos a partir de cuestionarios a la población (vid. en general, ROBERTS/HOUGH, 2005:18 y ss.; y en particular, GREEN, 2006, que plantea la necesidad de superar este método y avanzar en la línea de técnicas "deliberativas" de evaluación de la opinión publica).
}

Revista Española de Investigación Criminológica

Artículo 1, Número 6 (2008) $\quad$ www.criminología.net

ISSN: $1696-9219$ 
mucho menos, como punitivos. En los diferentes casos escenario propuestos los encuestados se decantan de forma mayoritaria por la aplicación de penas alternativas a la prisión, especialmente aquellas que son contempladas con capacidad rehabilitadora. De esta forma, los datos de la investigación apoyan claramente el uso de este tipo de penas como respuesta al delito, incluso en aquellos casos en que la ley penal se decanta por la prisión como pena. Por otra parte, preguntadas las personas que formaban la muestra por las causas de la delincuencia y su posible prevención, dan a la imposición de las penas un papel poco relevante, decantándose por medidas de carácter social. Ello es coherente con la comprensión de la delincuencia como un fenómeno que no ha de contemplarse desde una óptica individualista (como resultado de la libre voluntad del delincuente), sino como producto de diversos factores sociales y económicos. También es significativo el amplio apoyo que nuestra investigación acredita de la óptica rehabilitadora como criterio rector de la imposición y aplicación de la pena. Por tanto, de todo ello puede deducirse que la etiqueta de "benévola" con la que los ciudadanos suelen vincular la justicia penal es fruto, en realidad, del desconocimiento de la verdadera dimensión de la imposición y aplicación de las penas, producto fundamentalmente de la imagen sesgada que del funcionamiento del sistema penal les transmiten los medios de comunicación; ya que, de hecho, los datos de nuestra investigación muestran que a los que podrían considerarse "benévolos" son a los propios ciudadanos.

Se confirma así en nuestra investigación la "doble incomprensión" que caracteriza esta materia (vid. LARRAURI, 2006:19): de la opinión pública respecto del sistema penal (ya que en definitiva se piensa que es muy blando con la delincuencia) y de los políticos respecto de la opinión pública (ya que éstos creen que los ciudadanos son mucho más punitivos de lo que en realidad son).

Tercero. Por lo que se refiere a las "causas" o al "origen" de las actitudes punitivas, los factores que emergen a la hora de su posible explicación son de naturaleza diversa, lo cual dibuja un panorama complejo en la comprensión de los sentimientos punitivos. Así, en cuanto a las variables que hemos denominado "cognitivas", destaca la correlación existente entre la visión u opinión que los ciudadanos tienen de las penas impuestas por los jueces (como reacciones sistemáticamente "blandas" a la

Revista Española de Investigación Criminológica 
delincuencia) y la actitud punitiva. Una mejor información, pues, del funcionamiento real del sistema penal, parece que ayudaría a combatir las actitudes punitivas que se pueden generar como respuesta precisamente a la imagen sesgada (por benévola) que los medios de comunicación transmiten de la justicia penal. Por lo que se refiere a los factores emocionales, hay que subrayar, en particular, la desconfianza en la rehabilitación de los delincuentes y la visión de la delincuencia como producto fundamentalmente de la libre voluntad del individuo. Por tanto, la creencia en la rehabilitación y la comprensión de la delincuencia como un problema cuyas causas (y eventual remedio) hay que buscarlo en la propia estructura social se revelan como antídotos eficaces para el desarrollo de actitudes punitivas. Adicionalmente, por lo que respecta a los factores ideológicos, los resultados de la investigación muestran que aquellos que se autodefinen como de "Derechas" (o "Centro-Derecha") tienen una actitud más punitiva.

Cuarto. Por último, los datos de la investigación por lo que se refiere a la nacionalidad del delincuente o al rol que los encuestados atribuyen a la inmigración en la delincuencia, acreditan, en primer lugar, que la nacionalidad del delincuente es un factor que podría estar jugando un papel a la hora de decidir sobre la pena adecuada (particularmente si se trata de un magrebí). Y segundo, que los que vinculan inmigración y delincuencia tienen unas actitudes más punitivas.

Todo ello plantea muchos interrogantes futuros. En particular, si las mencionadas son las variables que alimentan los sentimientos punitivos, ¿cómo podemos actuar sobre ellas?. Ello, obviamente, es una cuestión que supera en mucho el objetivo de este estudio, que sólo pretende marcar un punto de partida en el estudio de las actitudes punitivas en nuestro país. 


\section{Referencias}

- CEREZO MIR, JOSÉ (2004): Curso de Derecho Penal Español, Parte General, Vol. I (Introducción), $6^{a}$ edición, Madrid: Tecnos.

- CID MOLINÉ, José (2005): “The Penitentiary System in Spain. The Use of Imprisonment, Living Conditions and Rehabilitation", Punishment and Society, 7(2):147-166.

- CID MOLINÉ, José (2007): "El incremento de la población reclusa en España entre 1996-2006: diagnóstico y remedios" (de próxima publicación).

- CID MOLINÉ, José / LARRAURI PIJOAN, Elena/ ESCOBAR MARULANDA, Gonzalo / LAHOZ LÓPEZ, Jennifer / LÓPEZ Y FERRER, Marayca / TÉBAR VILCHES, Beatriz / VARONA GÓMEZ, Daniel (2002): Jueces Penales y penas en España. Valencia: Tirant lo Blanch.

- DÍEZ RIPOLLÉS, José Luis (2004): "El nuevo modelo penal de la seguridad ciudadana", en Revista Electrónica de Ciencia Penal y Criminología, vol. 6, núm. 3, accesible en http://criminet.ugr.es/recpc/06/recpc06-03.pdf

- DÍEZ RIPOLLÉS, José Luis (2005): "De la sociedad del riesgo a la seguridad ciudadana: un debate desenfocado", en Revista Electrónica de Ciencia Penal y Criminología, vol. 7, núm. 1, accesible en http://criminet.ugr.es/recpc/07/recpc07-01.pdf

- DÍEZ RIPOLLÉS, J.L. / GIRÓN GONZÁLEZ-TORRE, F.J. / STANGELAND, P. / CEREZO DOMÍNGUEZ, A.I. (1996): Delincuencia y víctimas (Encuestas de victimización en Málaga), Valencia: Tirant lo Blanch.

- ESPC (2006): Enquesta de Seguretat Pública de Catalunya, Generalitat de Catalunya, Departament d'Interior en http://www.gencat.net/interior/docs/int_espc06.htm ).

- EU ICS (2005): The burden of crime in the EU, accesible en http://www.europeansafetyobservatory.eu/downloads/EUICS_The\%20Burde n\%20of\%20Crime\%20in\%20the\%20EU.pdf

- GARCÍA ESPAÑA, Elisa / PÉREZ JIMÉNEZ, Fátima (2005): Seguridad ciudadana y actividades policiales, Informe ODA 2005, Málaga: Instituto Andaluz Interuniversitario de Criminología, Fundación El Monte.

- GARCÍA ESPAÑA, Elisa / PÉREZ JIMÉNEZ, Fátima / BENÍTEZ JIMÉNEZ, M.José (2006): La delincuencia según las víctimas: un enfoque integrado a partir de una encuesta de victimación, Informe ODA 2006, Málaga: Instituto Andaluz Interuniversitario de Criminología, Fundación El Monte.

- GREEN, David A. (2006): "Public opinion versus public judgement about crime. Correcting de "Comedy of Errors", en British Journal of Criminology, vol. 46, págs. 131-154.

- HOUGH, Michael / ROBERTS, Julian (1998): Attitudes to punishment: findings from the British Crime Survey, Home Office Research Study 179, London: Home Office.

- LARRAURI PIJOAN, Elena (2005): "Populismo punitivo y penas alternativas a la prisión", en Bacigalupo, S. / Cancio, M. (coords.), Derecho Penal y Política Transnacional, Barcelona: Atelier, págs. 283-305.

- LARRAURI PIJOAN, Elena (2006): "Populismo punitivo...y cómo resistirlo", en Jueces para la Democracia, núm. 55, marzo, págs. 15-22.

Revista Española de Investigación Criminológica

Artículo 1, Número 6 (2008) www.criminología.net

ISSN: $1696-9219$ 
- LUQUE REINA, Eulàlia (1999): Les víctimes del delicte, Col-lecció Justícia i Societat, n. 20, Generalitat de Catalunya, Centre d'Estudis Jurídics i Formació Especialitzada.

- MARUNA, Shadd / KING, Anna (2004): "Public opinion and community penalties", a A, Bottoms / S. Rex / G. Robinson (edit.) Alternatives to Prison, Options for an insecure society, Willan Publishing, págs. 83-112.

- MEDINA ARIZA, Juanjo (2006): "Politics of crime in Spain, 1978-2004", en Punishment and Society, vol 8 (2), págs. 183-201.

- RECHEA ALBEROLA, Cristina / FERNÁNDEZ MOLINA, Esther / BENÍTEZ JIMÉNEZ, María José (2004): Tendencias sociales y delincuencia, Centro de Investigación en Criminología (Universidad de Castilla-La Mancha), núm. 11, accesible en http://www.uclm.es/Criminologia/pdf/11-2004.pdf

- ROBERTS, J. / STALANS, L.J. / INDERMAUR, D. / HOUGH, M. (2003): Penal Populism and Public Opinion, Oxford: Oxford University Press.

- ROBERTS, Julian / HOUGH, Mike (2005): Understanding public attitudes to criminal justice, Open University Press.

- VARONA GÓMEZ, Daniel (2008): “¿Son los españoles punitivos?: opinión pública y justicia penal en España” (de próxima publicación). 